\section{الدور الوظيفي لوسائل الإعلام في ظل جائحسة كورونا \\ دراسة ميدانية على عينة من الجمهور الفلسطيني في محافظة الخليل}

The Job Role of The Media in The Corona's Pandemic

A Field Study on A Sample of the Palestinian Public in Hebron Governorate

\author{
سمير سليمان الجمل1** باسم فؤاد أبو داود2 \\ Sameer.S. Al-Jamal1*, Basem. F. Abu Dawuod ${ }^{2}$ \\ 'كلية العلوم الإدارية، جامعة فلسطين الأهلية، فلسطين، كلية العلوم الإدارية، جامعة فلسطين التقنية-خضوري، فلسطين
}

${ }^{1}$ Faculty of Administrative and Finance Sciences. Palestine Ahliya University, Palestine, ${ }^{2}$ Faculty of Business and Economics. Palestine Technical University-Kadoori-Palestine.

المستـخلص هدفت الدراسة إلى التعرف على الدور الوظيفي للإعلام في ظل جائحة كورونا من وجهة نظر عينة من

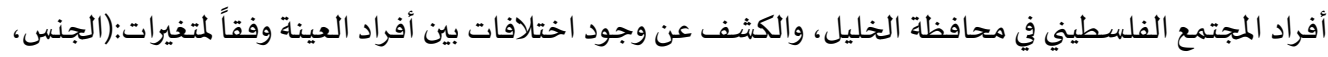

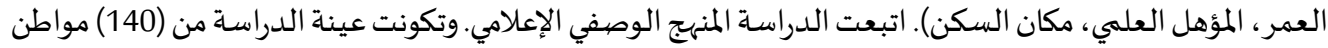

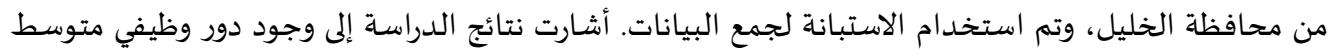

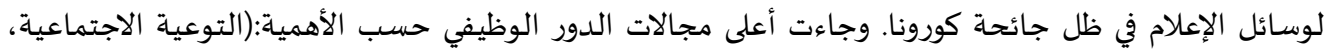

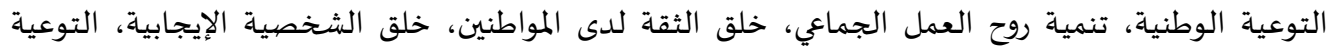

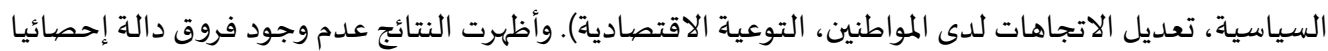

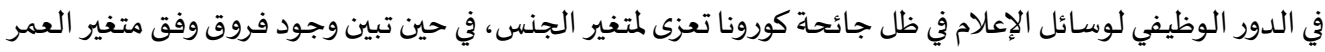

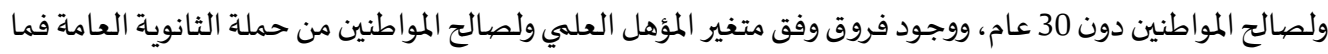

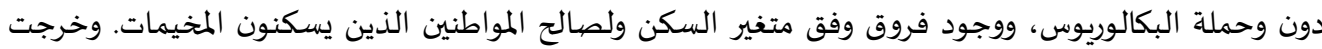

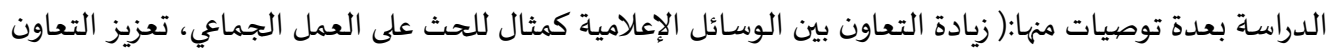

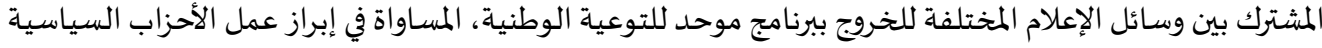

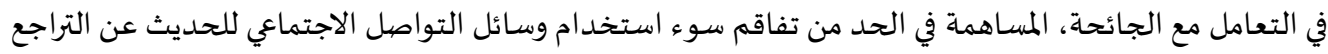

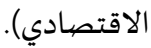
الكلمات المفتاحية: الدور الوظيفي، وسائل الإعلام، جائحة كورونا، محافظة الخليل.

Abstract: The study aimed to identify the functional role of the media in light of the Corona pandemic from the point of view of a sample of Palestinian community members in Hebron, and to uncover the existence of differences between members of the sample according to variables: (gender, age, educational qualification, place of residence). The study followed the Media survey method. The sample of the study consisted of (140) citizens from Hebron, and the questionnaire was used to collect data. The results of the study indicated an average functional role for the media in the light of the Corona pandemic. The highest job role areas came according to importance: (social awareness, national awareness, developing teamwork spirit, creating confidence among citizens, creating positive personality, political 
education, changing attitudes among citizens, economic awareness). The results showed that there were no statistically significant differences in the job role of the media in light of the Corona pandemic attributable to the gender variable, while differences were found according to the age variable and for the benefit of citizens under 30 years, and the existence of differences according to the variable of the educational qualification and for the benefit of citizens of high school holders and below and undergraduate holders And the existence of differences according to the housing variable and in favor of the citizens who live in the camps. The study came out with several recommendations, including:(Increase cooperation between media outlets as an example to urge collective action, enhance joint cooperation between different media outlets to produce a unified national awareness program, equality in highlighting the work of political parties in dealing with the pandemic, con tribute to reducing the exacerbation of social media misuse to talk about economic decline).

Keywords: career role, media, Corona pandemic, Hebron Governorate.

يعتبر الإعلام أهم وسيلة من وسائل التأثير الجماهيري، وقد لعبت دوراً كبيراً في حياة المجتمعات الإنسانية، ففي العصر

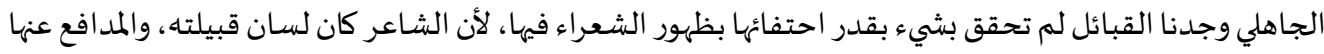
أمام الآخرين، أي أنه كان وسيلتها الإعلامية وقت ذاء ذاك (ميرزا، 2006).

بدأ العالم يواجه جائحة، اجتاحت معظم أقطار العالم، ابتدأت في مقاطعة ووهان في جمهورية الصين، ثم انتقلت إلى دأل باقي دول العالم بنسب متفاوتة، وقد ابتدأت تلك الجائحة في الأراضي الفلسطينية من مخالطين لسياح يونانيين في

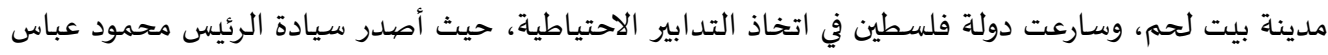

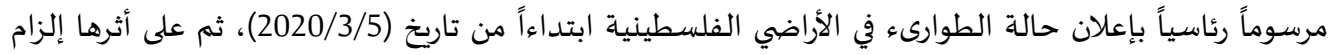

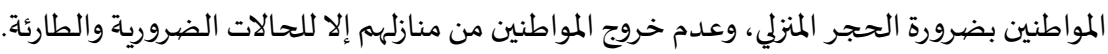

ويعد الإعلام من بين أكثر الوسائل اهتماما وقوة في معالجاة الأزمات أيا كان نوع تلك الأزمات، سياسية، اقتصادية أو اجتماعياة، مما ينتج عن التفاعل والحراك السياسي والاجتماعي. حيث أضحت الأوعية الإعلامية تؤدي دوراً مؤثرا في الإني

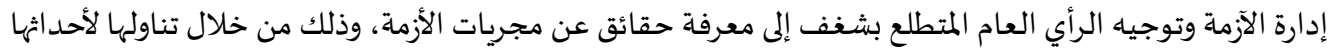

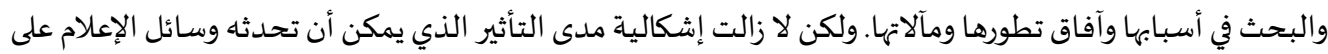
الأفراد والمجتمع محل خلاف بين المهتمين على مستوى الرأي العام والفاعلين الإعلاميين لاسيما عند تأجيج الأزمات.

ويتلخص محتوى هذه الإشكالية في أن البعض يتهم وسائل الإعلام ويصفها بالمسئولية عن انحطاط الذوق العام

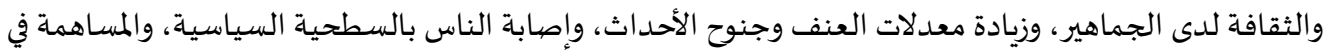

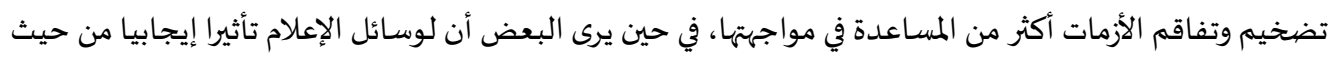

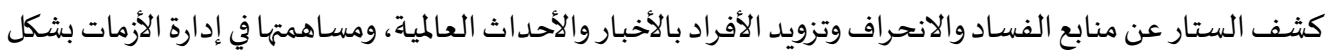

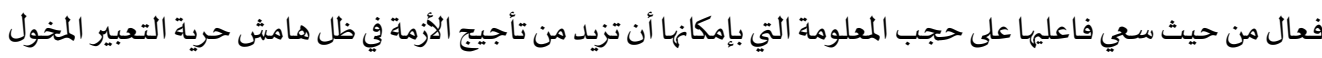

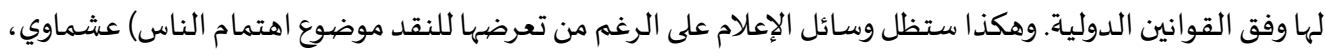


مشكلة الدراسـة وأسئلتها:

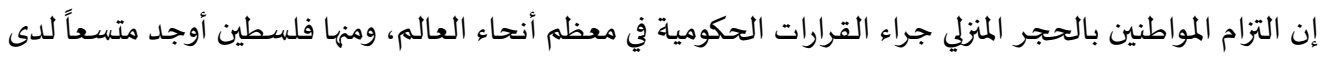

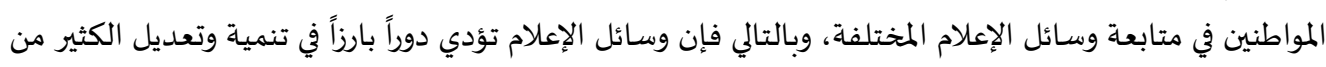
السلوكات والاتجاهات، لذا يمكن حصر مشكلة الدراسة من خلال السؤال الرئيس الآتي:

السؤال الرئيس: ما الدور الوظيفي لوسائل الإعلام (تنمية روح العمل الجماعي، التوعية الوطنية، التوعية

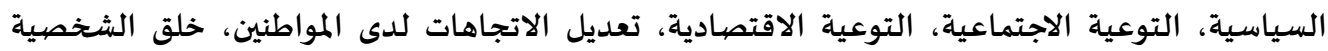

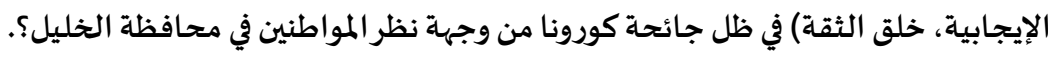
وينبثق عنه الأسئلة الفرعية التالية:

س1) ما دوروسائل الإعلام في تنمية روح العمل الجماعي لدى المواطنين في محافظة الخليل؟ س2) ما دوروسائل الإعلام في التوعية الوطنية لدى المواطنين في محافظة الخليل؟ س3) ما دوروسائل الإعلام في التوعية السياسية لدى المواطنين في محافظة الخليل؟ س4) ما دوروسائل الإعلام في التوعية الاجتماعية لدى المواطنين في محافظة الخليل؟ س5) ما دوروسائل الإعلام في التوعية الاقتصادية لدى المواطنين في محافظة الخليل؟ س6) ما دوروسائل الإعلام في تعديل الاتجاهات لدى المواطنين في محافظة الخليل؟ س7) ما دوروسائل الإعلام في خلق الشخصية الإيجابية لدى المواطنين في محافظة الخليل؟ س8) ما دوروسائل الإعلام في خلق الثقة لدى المواطنين في محافظة الخليل؟ فرضيات الدراسة: لا توجد فروق ذات دلالة إحصائية عند مستوى الدلالة (ي0.05 م) في الدور الوظيفي لوسائل الإعلام وفق متغيرات:

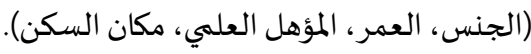

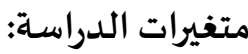
المتغيرات الديموغر افية والمستقلة: • الجنس: وله مستويان:(ذكر ، أنثى).

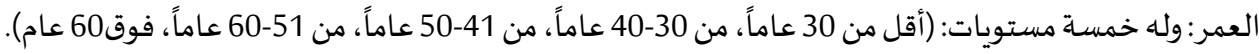

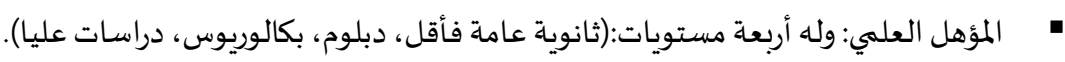

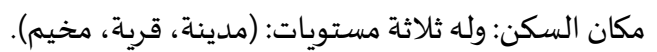
المتغير التابع: الدور الوظيفي لوسائل الإعلام في ظل جائحة كورونا. أهداف الدراسـة: - ماف: هدفت الدراسـة إلى الكشف عن: 


$$
\begin{aligned}
& \text { دور وسائل الإعلام في تنمية روح العمل الجماعي. } \\
& \text { دور وسائل الإعلام في التوعية الوطنية، والسياسية والاجتماعية والاقتصادية. }
\end{aligned}
$$

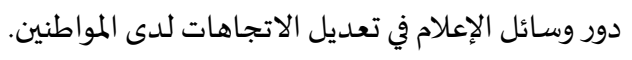

$$
\begin{aligned}
& \text { دور وسائل الإعلام في خلق الشخصية الإيجابية. } \\
& \text { دور وسائل الإعلام في خلق الثقة لدى المواطنين. }
\end{aligned}
$$

\section{أهمية الدراسة:}

$$
\text { تكمن أهمية الدراسـة بما يلي: }
$$

محاولة وضيع الحلول للتخلص من الآثار السلبية لوسائل الإعلام.

تعتبر هذه الدراسة من الدراسات القليلة -على حد علم الباحثين-والتي تناولت الدور الوظيفي لوسائل الإعلام في ظل جائحة كورونا، حيث لم يتم تناول هذا الموضوع في البيئة الفلسطينية، مما قد يشكل إثراءً للمكتبة التربوية

$$
\text { بالجديد من الدراسات. }
$$

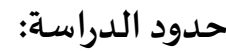

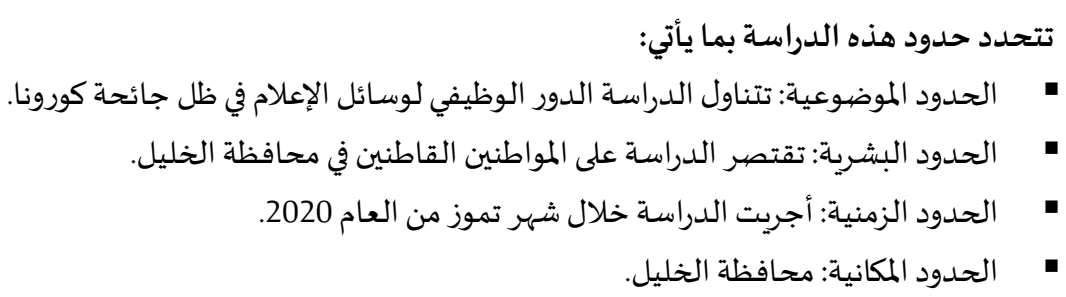

مصرطلحات الدراسـة:

الإعلام: هو إحدى الوسائل أو المنظمات التجاريّة التي تتولى مسؤوليّة نشر الأخبار وإيصال المعلومات للأفراد، وتكون

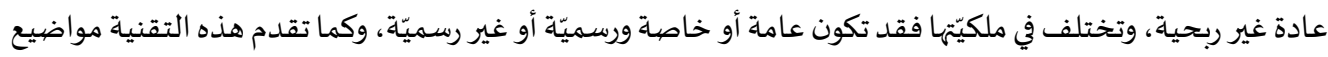
مختلفة للجمهور كالترفيا والمعلومات والتسلية والأخبار وغيرها ما يهم الفرد، وزاد انتشار رقعة الإعلام في الآونة الأخيرة مع ظهور الثورة التلفازيّة، ويكون إيصال هذه المعلومات بواسطة تقنيات أو وسائل خاصية بها تسمّى وسائل الإعلام (الحياري، 2016).

ويعرف أيضاً بأنه: نشر الحقائق، الأفكار، الأخبار، الآراء بين الجماهير بوسائل الإعلام المختلفة كالصحافة والإذاعة

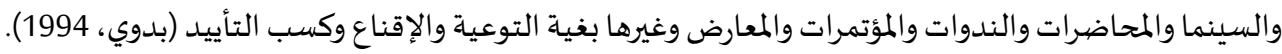
وسائل الإعلام: يعرفها الباحثان بأنها: الوسائل التي تقوم بتوصيل المعلومات والأخبار إلى الناس، وتشمل الوسائل المسموعة(كالراديو)، والمكتوبة (كالصحف والمجلات)، والمرئية (كالتلفزيون والسينما)، وتشمل وسائل الإعلام الحديثانة مثل الانترنت، ووسائل التواصل الاجتماعي بمختلف وأمتوبه المواعها. الجائحة: وردت لفظة جائحة في كثير من المعاجم والقواميس العربية على أها: جمع جوائح وهي داهية، مصيبة تحل

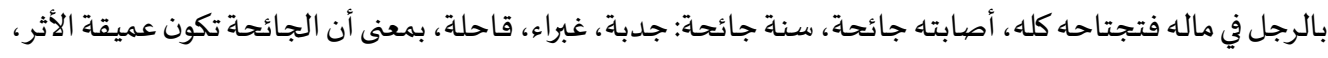
المادي والمعنوي، فالجائحة أخطر وأفتك من الوباء فهي تنتشر في جزء كبير من الكرة الأرضية ( المعاني الجامع (/https://ontology.birzeit.edu/term) 
جائحة فيروس كورونا: سُجلت التقارير الأولية لبدء انتشاره في منتصف شهر ديسمبر من عام 2019، وما زالت الحالات المسجلة بالإصابة باه في ارتفاع متسارع في مطلع عام 2020، وقد أعلنت السلطات الصات الصينية أنّ حالات الإصابة الأولى

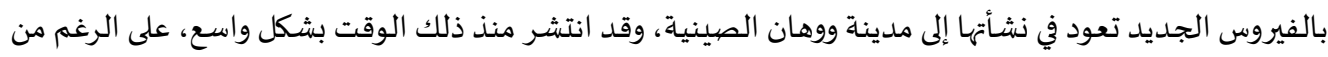

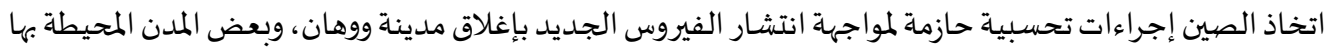
بمنع السفر منها أو إليها عبر جميع وسائل النقل.

جائحة كورونا: هي جائحةٌ عالميةٌ جارية لمرض فيروس كورونا 2019 (كوفيد-19) والذي يحدثُ بسبب فيروس كورونا

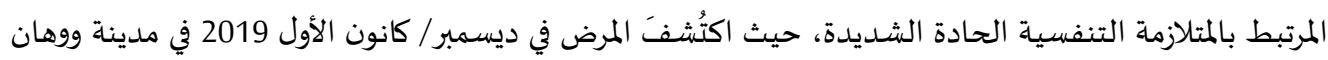
وسط الصين، وأُطلقَ عليه اسم nCoV-2019 وقد صنّفتأُ منظمة الصحة العالمية في (11 مارس 2020 ) جائحة.

يستطيعُ الفيروس أن ينتشر بين البشر مباشرةً، ويبدو أنّ معدل انتقاله (معدل الإصابة)، قد ارتفع في منتصف يناير

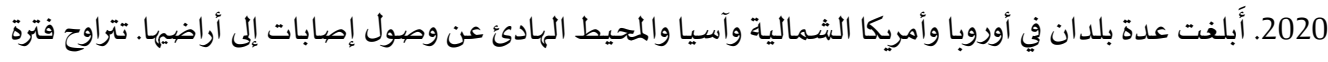

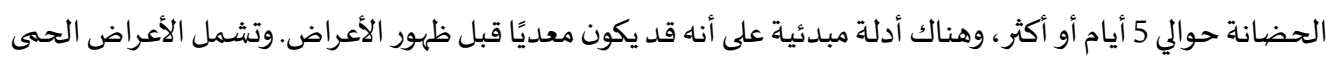
والسعال وصعوبة التنفس، وقد تؤدي إلى الوفاة.

وكرد صيني أولي، قامت حكومات وهان و15 مدينة في محيط مقاطعة هوبي بعمل حظر تنقل شمل أكثر من 57 مليون شخص. انطوى ذلك على إيقاف جميع وسائل النقل العام في المناطق الحضرية والنقل إلى الخارج عن طريق القطار،

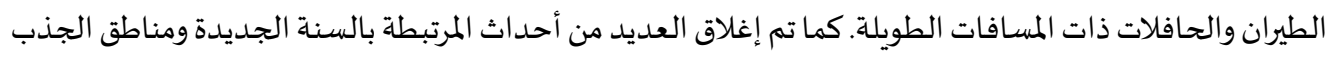

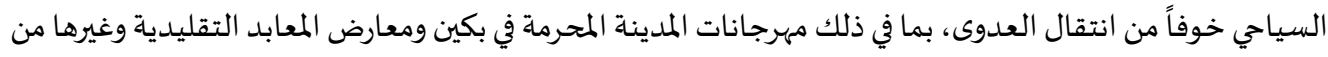

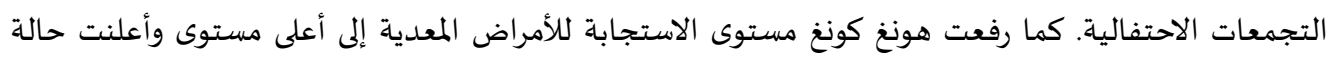

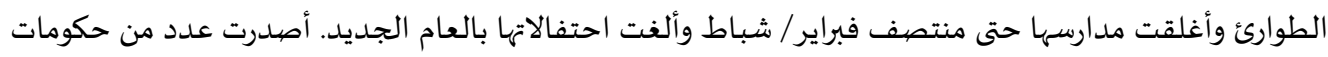

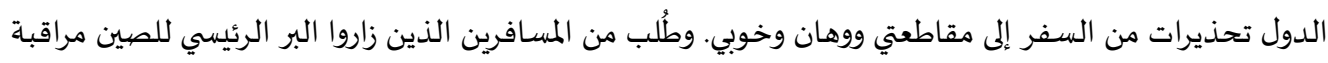

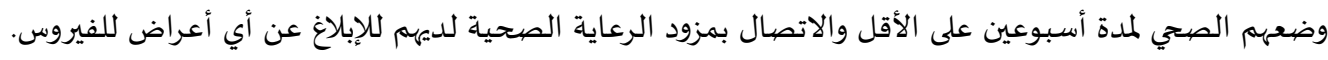

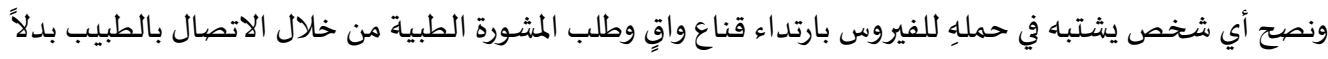

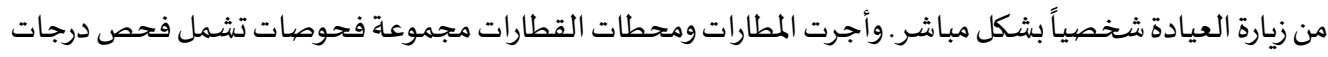
الحرارة ونشرت الإعلانات الصحية وكذلك مختصر للمعلومات على لوحات إعلانات لأجل التعرف على حاملي الفيروس( ويكيديا، 2020(/https://ar.wikipedia.org/wiki).

الإعلام: للإعلام دور متزايد ومهم وجوهري في تغطيته لإدارة الأزمات، نظراً لماله من قدرات هائلة، تمثل في انتقاله بسرعة

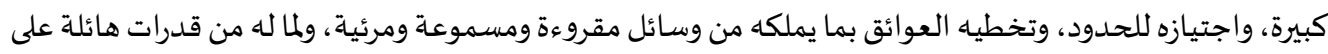
التأثير النفسي على الأفراد والسيطرة الفكرية والإقناع للجمههور في المجتمعات المختلفة، ومن ثم امكانية التحكم في مهي

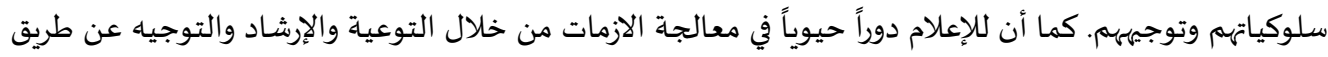

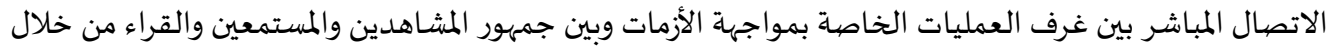
تحذيرهم من الأخطار المحدقة التي تم التنبؤ بها. ولإعلام دور مههم في التخفيف من حدة الأزمات من خلال تلمهات تزويد

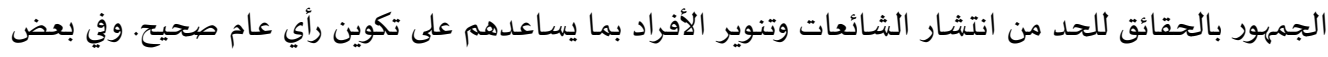
الأحيان يكون تأثير الإعلام في الأزمات "سلبيًا"، من خلال نشر الشائعات والمغالطات المات (شبكة النبأ المعلوماتية، 2020).

\section{دور الإعلام والاتصيالات في المراحل المختلفة للأزمة:}

ينطلق دور الإعلام والاتصالات في دورة حياة الأزمة من ثلاثة مبادىء رئيسـة هي (محمود، 2003):

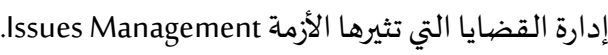

التخطيط لمنع الأزمة Planning-Prevention. الإنجاز والعمل على انحسار الأزمة Implementation. 
المرحلة الأولى: دور الإعلام والاتصال في إدارة القضايا المتعلقة بالأزمة، ويتمثل في:

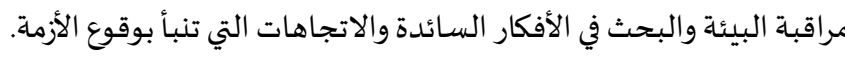

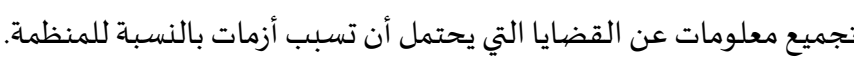

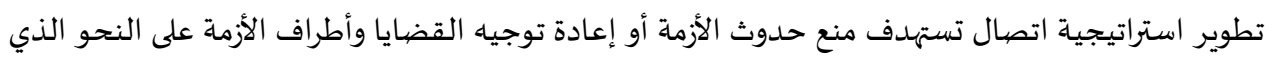

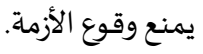

المرحلة الثانية: دور الإعلام والاتصبال في المشاركة في التخطيط لمنع الأزمة، ويتمثل في:

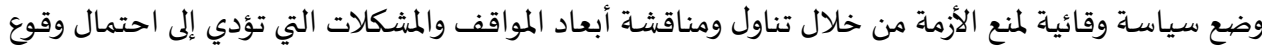

$$
\text { الأزمات والتنبيه إلهيها. }
$$

إيجاد قنوات من الاتصال بين وسائل الإعلام وفريق إدارة الأزمة في المنظمة.

الوصول إلى ممثلي المنظمة للتعامل مع الإعلام وتوصيل الحقائق إلى الجماهيل الماهير.

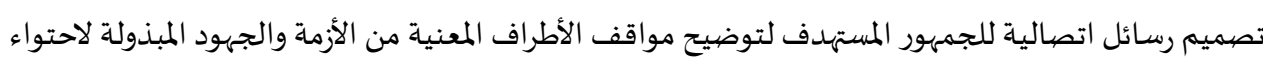

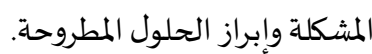

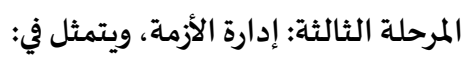
• العمل على استمرار التدفق السريع للمعلومات والبيانات المتعلقة بالأزمة.

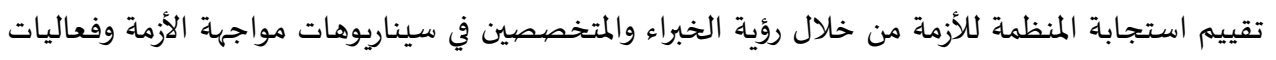
التعامل معها من جانب المنظمة.

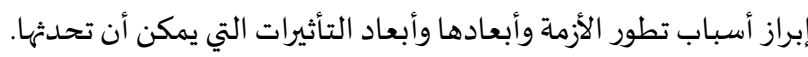

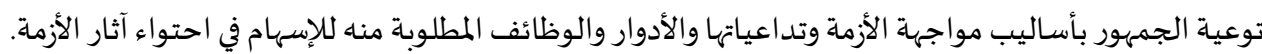

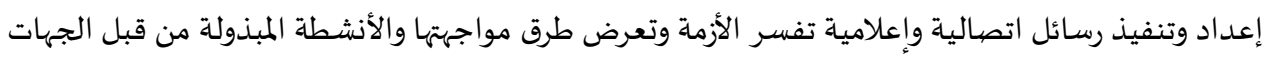
المعنية بالأزمة لاحتواء آثارها.

المرحلة الر ابعة: دور الإعلام والاتصال بعد انحسار الأزمة، ويتمثل في:

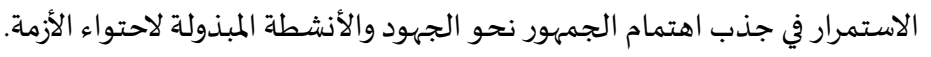

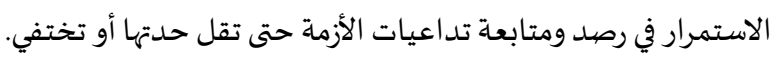

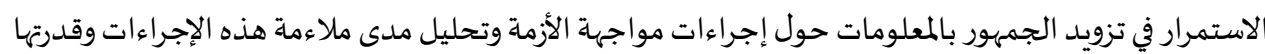
على عدم تكرار الأزمة في المستقبل.

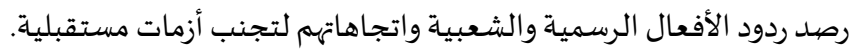
تطوير استراتيجية اتصال تستفيد من الخبرة الحالية في مواجهة الأزمة للاستعانة بها والبناء عليها في مواجهة أزمات التهات مشابهة.

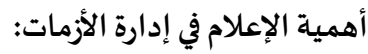

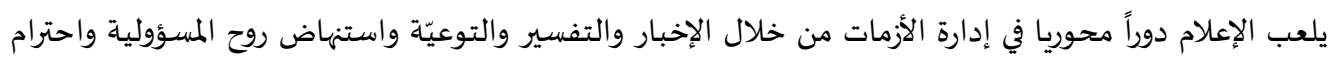

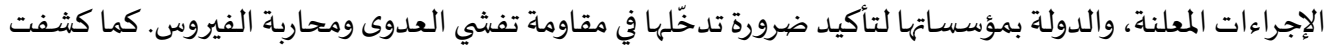

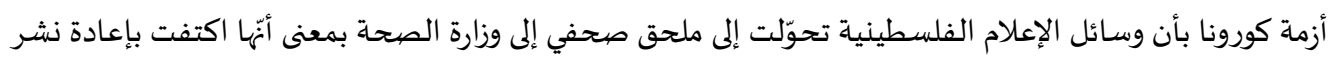

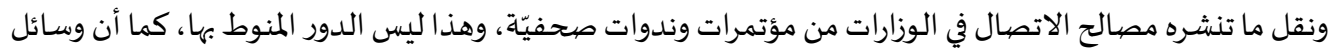

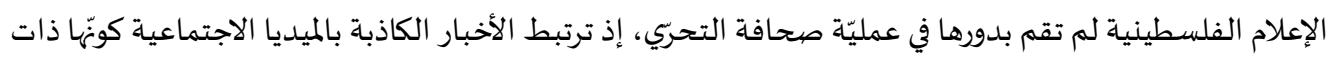

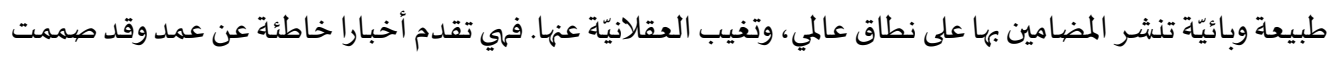

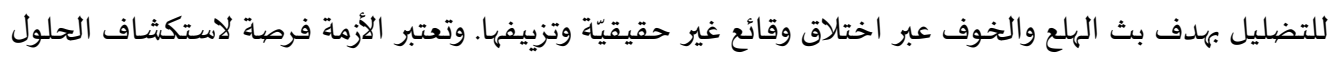


الجديدة لتجديد الذات، وأخذ القرارات لتقييم المنظومة الإعلاميّة في فلسطين وإعادة ترتيها وأنّ لا تنحصر أدوار وسائل الإعلام الفلسطيني في دور واحد وهو نقل المعلومة والخبر، على حساب أدوار التحري والتفسير والاستقصياء والتعليق، فإذا تخلىّ الصحفي عن واحدة فلا تستقيم العمليّة (حمودة، 2020).

ويحتل البعد الإعلامي مكانة مهمة في أدبيات دراسة الأزمات، حيث يعد الإعلام أداة رئيسية وفعالة من أدوات إدارة الآزمة

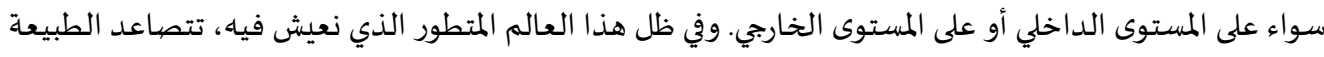
التنافسية التي تجعل من الأزمات التي تهدد النظام شيئا واردا، وتظهر الجهود الإعلامياة كإحدى الدئي الدعامات الأساسية.

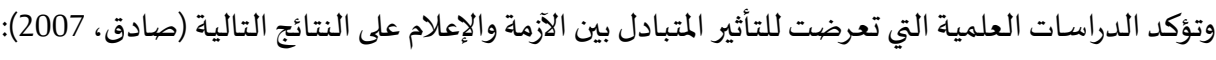

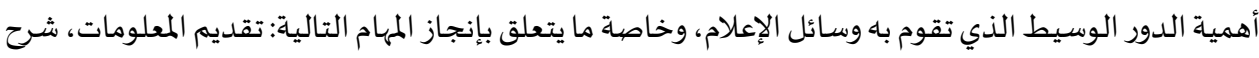

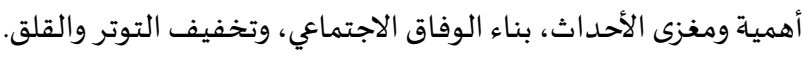

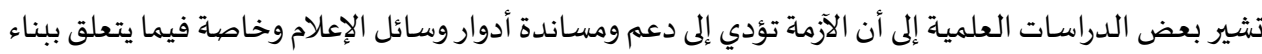
الوفاق وتخفيف التوتر، بينما يرى آخرون أن ظروف الآزمة وما تفرضاء من تداخلات وقيود وإجراءات سوف تؤدي إلى تحجيم دور الإعلام. تجذب الأزمة اهتمام وسائل الإعلام، ولكتها أيضا وبالمقابل تجذب الإبام اهتمام الرأي العام بوسائل الإعلام، الذي يصبح أكثر تعرضا واستخداما لها، وهذا ما يفسر حقيقة، أن ظروف الأزمة تتميز دائما بالاستخدام المكثف لوسائل المائل الإعلام.

وقامت دراسات أخرى بوصف دور وسائل الإعلام في إدارة الأزمات الداخلية والخارجية في كل من الأنظمة التعددية والأنظمة غير التعددية، وذلك لتبيين مدى أهمية حرية التعبير والإعلام في رصدد وتغطية الأزمات الداخلية والخارجية.

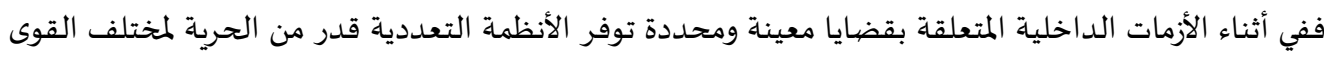
الفاعلة لأن تعبر عن رأيها، وتقدم برنامجها، وربما تشترك في عملية الصراع المحتدم لحل الأزمة، ومن تلك القوى وسائل

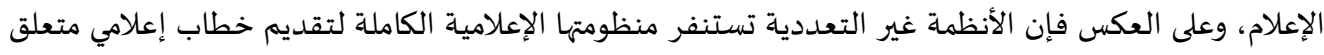

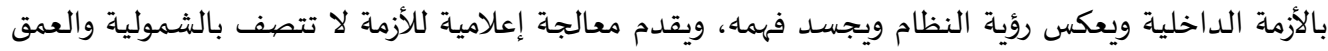

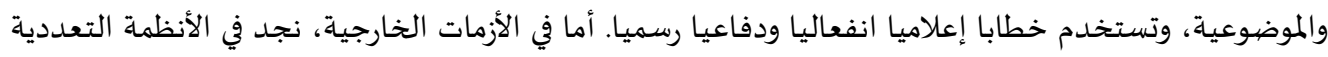
اختلاف المواقف بين وسائل الإعلام حول الآزمة الخارجية، يعكس في حقيقته وجوهره اختلاف مواقع القوى المحلية وتناقض مصالحها، مما يعكس مناخا ليبراليا ديمقراطيا وحرية إعلامياة. وتقف وسائل الإعلام وراء النظام السائد في

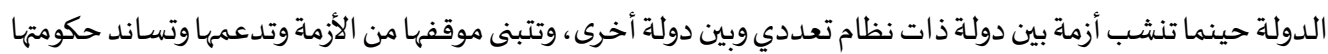
في صراعها ضد الدولة الأخرى، حيث نجد تجانس وتماسك إزاء المسائل التي تهم البلد ككل، والنظام كوحدة. وعلى وعلى النه العكس نجد في الأنظمة غير التعددية أن وسائل الإعلام تكون تابعة للدولة، وتكون مهمتها خدمة النظام القائم (صادق،

(2007

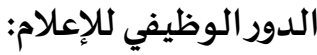

توجد عدة وظائف للإعلام واهمها ما يلي (شبكة النباً المعلوماتية، 2020): اشباع رغبة الجمهور في التعليم: وهو من الوظائف المهمة التي تقع على عاتق الاعلام من خلال وسائله المختلفة،

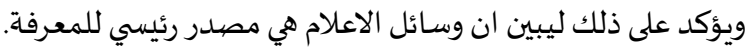

تعبئة الجماهير والهاهها بالفكر والمبادئ وروح العمل الجماعي: وهو الامر الذي يدفع بالمجتمع الانساني نحو التطور والابداع، وخاصية من خلال جمهور المثقفين.

دفع ودعم التنمية الوطنية والاقتصادية والاجتماعية:وسائل الاعلام هي أفضل وسيلة يمكن ان تستخدم لإحداث

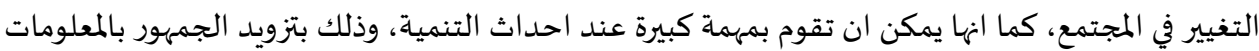
عن المستجدات في كافة المجالات كافة. 
التنمية السياسية: من خلال افراد مساحات جيدة تخصصها الرسالة الاعلامية للتثقيف السياسي، والتنشئة السياسية، كذلك تبصير الجمهور بأهمية المشاركة السياسية في إطار العلاقة الوثيقة بين البنيان الاعلامي وبنيان

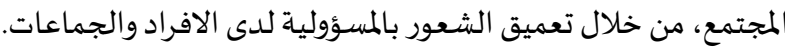

التوعية الوطنية: للإعلام دور في تعميق روح الانتماء واذكاء مشاعر الانتماء الوطني والايمان بوحدة الامة ورسالتها الحضيارياة.

احداث التحول وتغيير الاتجاهات: ان محاولات الاقناع المتتالية من اجل تغيير الاتجاهات من المهام الاعلامية البارزة التي تسعى وسائل الاعلام لتحقيقها.

التنشئة والتوعية الاجتماعية للفرد: للإعلام دور كبير في عملية التربية الفكرية السليمة للأفراد وتدريبهم العقلي على اصدار الاحكام السليمة، من خلال عرض مواقف مماثلة تستلهم حلولا مثالية، وكذلك التنشئة الاجتماعية الصحيحة للأفراد.

صياغة المجتمعات: حتى يبرز المجتمع الجماهيري كقوة لها وزنها في تسيير الحياة السياسية والاقتصادية

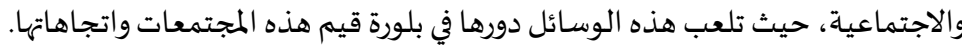

خلق راي عام:وذلك بعرض الحقائق الثابتة امام الجمههور جميعها، وامداده بالمعلومات الصحيحة والدقيقة والتي تساعده في تكوين راي صائب في قضايا وموضوعات الساعة، فمهمة وسائل الاعلام هنا الوصول بجمهور المتلقين للرسالة الاعلامية الى اقصى درجة ممكنة من المعرفة والوعي والادراك.

خلق الشخصية الايجابية: وهي تلك الشخصية النشطة في التفاعل الانساني والتي تتقبل بسهولة وتفهم حضيارات الامم الاخرى وتعمل على اللحاق بركب التطور في مرونة ورغبة صادية التحقة.

نقل حضيارات الامم الاخرى: من خلال التكنولوجيا المبهرة القائمة على الصيوت والصورة والحركة السريعة في نقل

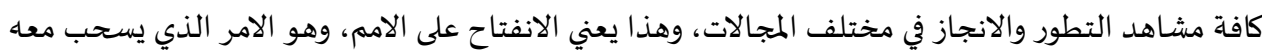
الشعوب الراكدة والامم المتخلفة الى ركب الحضيارة.

دعم القيم الروحية والايديولوجية: تعبئة الجماهير والهامها بالمثل والافكار والمبادئ وروح العمل الجماعي وتغذية

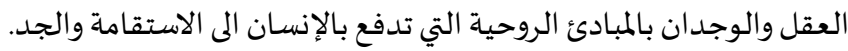

خلق الثقة: فوسائل الاعلام بما تتبناه من القيم والتعليمات الاخلاقية والمثل العليا، وبما تنتهجهاء من بث لقواعد

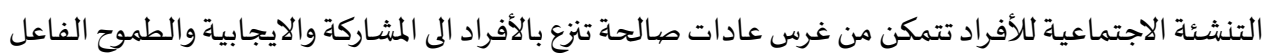
وتولد الثقة في النفس وفي الاخرين.

التحديث: من خلال المساهمة في ايجاد بنيات تلاحق التطور وتستجيب له، بالإضافة الى التطور في القيم والمعتقدات، ويرتبط التحديث ببناء الامة كهدف للسياسة العامة.

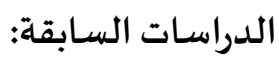

أجرى الشمري(2018) دراسة هدفت لبيان ما إذا كانت التقنيات الإعلامية الجديدة داخل المنزل تعمل على جلب أجيال

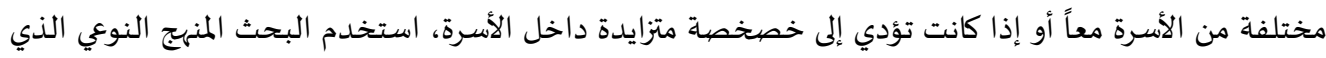

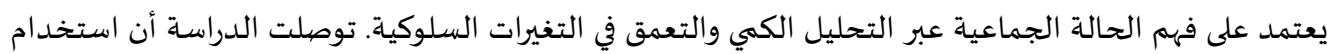


الشبكات الاجتماعية لا يرتبط بالرضا العام عن العلاقات، وأن تكنولوجيا الاتصال والإعلام تؤثر على العلاقات والسعادة بشكل متفاوت، واستخدام الانترنت في الليل لا يؤثر على العلاقة بالوالدين.

كما أجرى عايد (2017) دراسة هدفت إلى بيان مدى تأثير تكنولوجيا الإعلام والاتصال على قيم المجتمع الجزائري

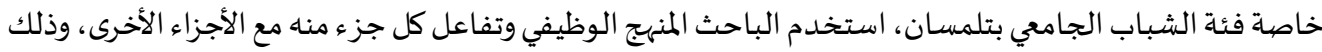

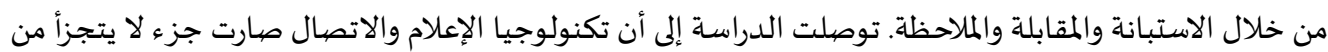

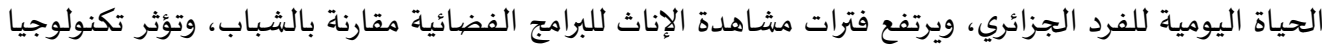

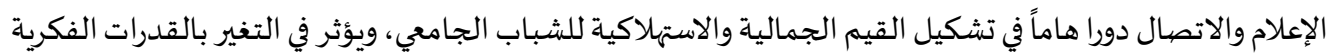

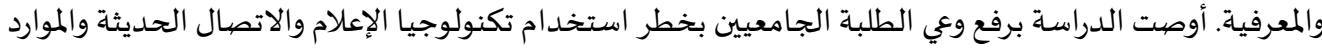

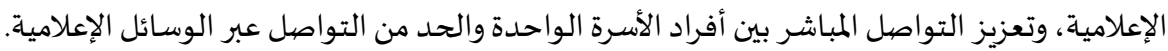

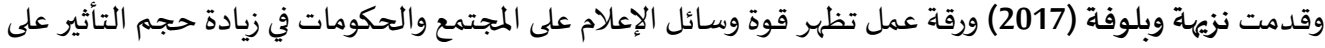

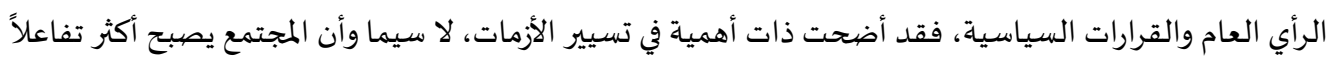

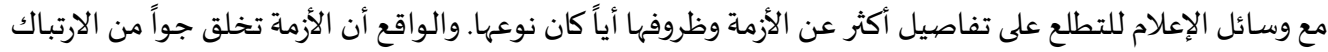

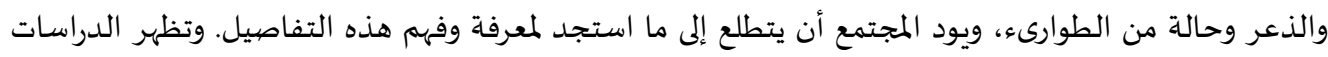

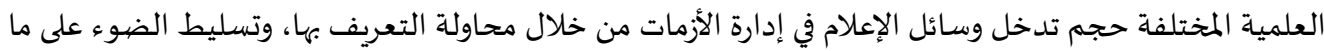

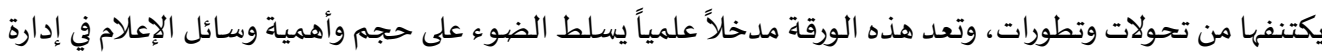
الأزمات وفهم التحديات التي تواجه عملها.

وأجرت سالم (2016) دراسة هدفت إلى تقديم إطارا نظريا برؤية متكاملة عن اتصالات الأزمات والكوارث عبر وسائل

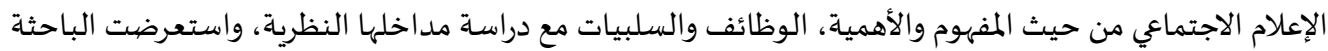

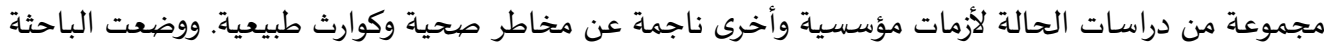

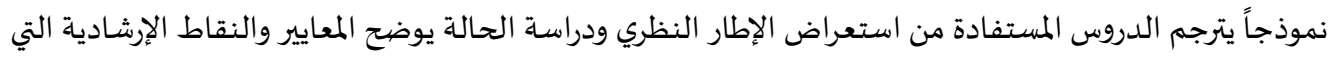

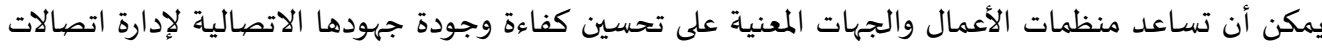

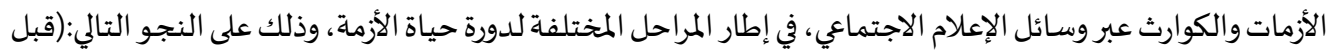

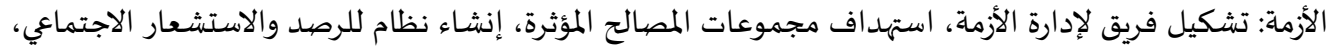

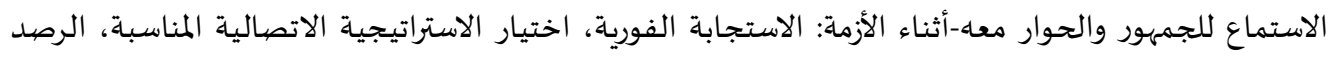
والمراقبة، إدارة الشائعات-بعد الأزمة: تقييم الاستجابة الاتصالية، استمرار التواصل مع الإسة الجمههور، التصحيح البناء).

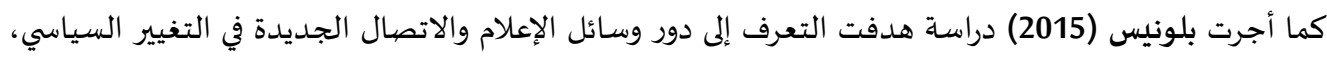

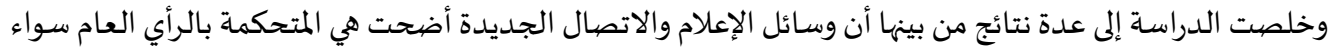

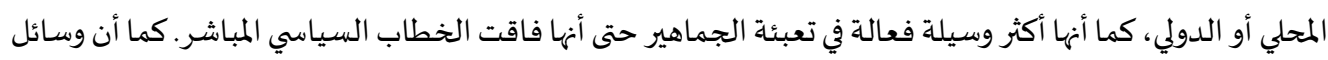

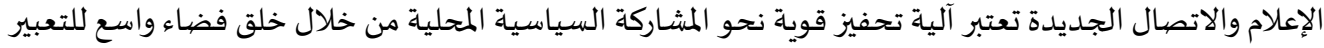

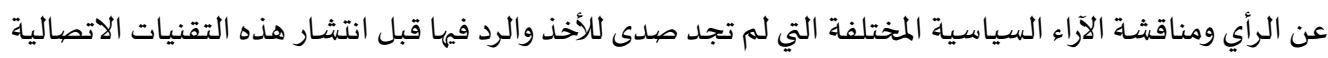

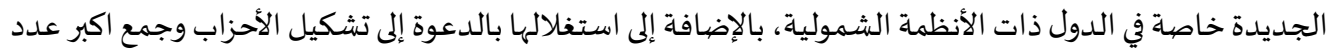

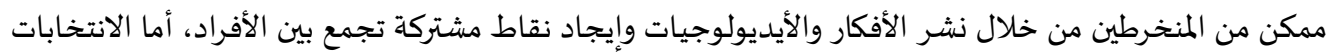

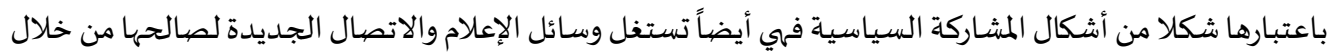

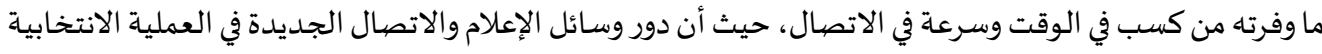

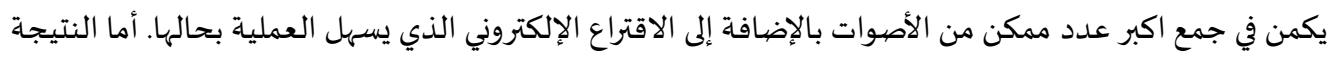

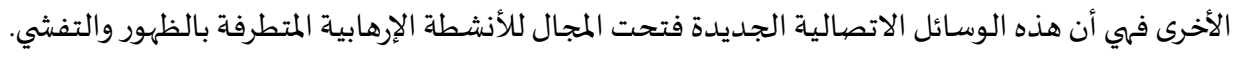


تعقيب على الدراسـات السـابقة:

بعد الاستعراض السابق للدراسات السابقة توصل الباحثان إلى إن موضوع الإعلام ودوره في إدارة الأزمات قد حظي

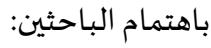

-تناولت دراسات عديدة اتصالات الأزمات والكوارث عبر وسائل الإعلام الاجتماعي مثل دراسة سالم(2016)، وتناولت

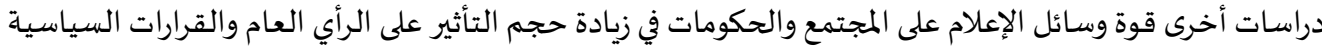

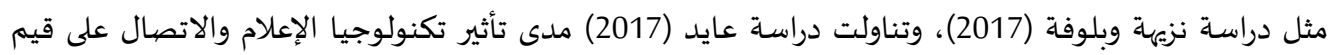

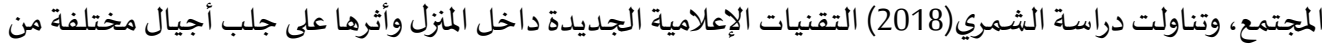

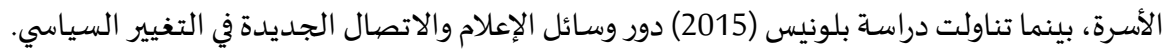

-استفاد الباحثان من هذه الدراسات في التعرف إلى مجالات الدراسة ومتغيراتها، كما استفادا من النتائج والتوصيات

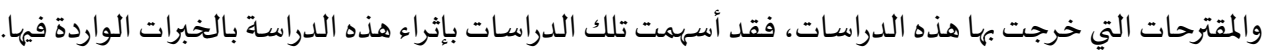

ـأهم ما يميز هذه الدراسة أهها عنيت بمعرفة الدور الوظيفي لوسائل الإعلام في ظلل جائحة كورونا من وجهة نظر

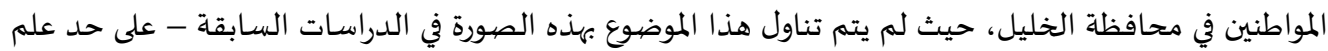

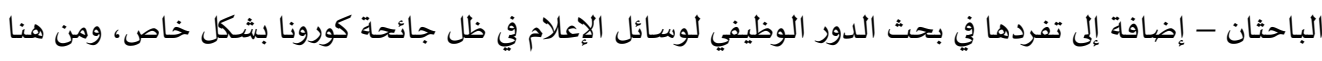
جاءت هذه الدراسة لتسلط الضوء على الدور الذي قامت بهان وسائل الإعلام بكافة أنواعها في أزمة كورونا.

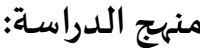

أجريت هذه الدراسة خلال شهر حزيران من العام 2020، واستخدم الباحثان في إنجازها المنهج المستي الإعلامي لعينة الدراسة لملاءمته لمثل هذا النوع من الدراسات.

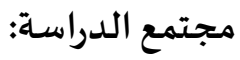

تكون مجتمع الدراسة من جميع المواطنين البالغين (فوق 18 عام) القاطنين في محافظة الخليل.

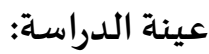

قام الباحثان بأخذ عينة عشوائية من أفراد المجتمع الفلسطيني، باستخدام استبانة إلكترونية تم توزيعها بشكل عشوائي، حيث تم تعبئة (140) استبانة، والجدول (1) يبين توزيع عينة الدراسة حسب المتغيرات الديموغرافية: جدول (1): توزيع أفراد عينة الدراسة حسب متغيرات الدراسة.

\begin{tabular}{|c|c|c|c|c|}
\hline النسبة المئوية & العدد & المتغيرات & & 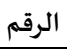 \\
\hline$\% 63.6$ & 89 & ذكر & \multirow{2}{*}{ الجنس } & \multirow{2}{*}{1} \\
\hline$\% 36.4$ & 51 & أنثى & & \\
\hline$\% 52.2$ & 73 & أقل من 30 عاماً. & \multirow{5}{*}{ العمر } & \multirow{5}{*}{2} \\
\hline$\% 15$ & 21 & من 30-40 عاماً. & & \\
\hline$\% 15.7$ & 22 & من 41-50 عاماً. & & \\
\hline$\% 10.7$ & 15 & 60-51 ع عاماً. & & \\
\hline$\% 6.4$ & 9 & فوق 60 عام. & & \\
\hline$\% 10$ & 14 & ثانوية عامة فما دون & \multirow{4}{*}{ المؤهل العلمي } & \multirow{4}{*}{3} \\
\hline$\% 5$ & 7 & دبلوم & & \\
\hline$\% 60.7$ & 85 & بكالوريوس & & \\
\hline$\% 24.3$ & 34 & دراسـات عليا & & \\
\hline
\end{tabular}




\begin{tabular}{lllll}
\hline$\% 61.4$ & 86 & & & \\
$\% 22.9$ & 32 & مدينة & & 4 \\
$\% 15.7$ & 22 & مخرية & & \\
\hline
\end{tabular}

أداة الدراسـة:

تم إعداد استبانة لقياس الدور الوظيفي لوسائل الإعلام في ظل جائحة كورونا، بالاستناد إلى الأدب التربوي والدراسـات السابقة وخبرة الباحثين، وقد تكونت الاستبانة من قسمين:

القسم الأول: يحتوي على البيانات الأولية عن الشخص الذي يقوم بتعبئة الاستبانة وهي: (الجنس، العمر ، المؤهل

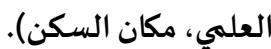
القسم الثاني: يقيس الدور الوظيفي لوسائل الإعلام في ظل جائحة كورونا، ويتكون من ثمانية مجالات: المجال الأول: تنمية روح العمل الجماعي، ويتكون من (5) فقرات. المجال الثاني: التوعية الوطنية، ويتكون من (4) فقرات. المجال الثالث: التوعية السياسية، ويتكون من (5) فقرات. المجال الر ابع: التوعية الاجتماعية، ويتكون من (5) فقرات. المجال الخامس: التوعية الاقتصادياة، ويتكون من (5) فقرات. المجال السـادس: تعديل الاتجاهات لدى المواطنين، ويتكون من (6) فقرات. المجال السابع: خلق الشخصية الإيجابية، ويتكون من (5) فقرات. المجال الثامن: خلق الثقة لدى المواطنين، ويتكون من (6) فقرات.

صدق الأداة:

يعبر صدق الأداة عن مدى صلاحية الأداة المستخدمة لقياس ما وضعت لقياساه، وعرض الباحثان الاستبانة على عدد من المختصين وذوي الخبرة في عدد من الجامعات الفلسطينية من حملة شهادات الدكتوراه، وأعيد صياغة الاستبانة ليُصبح عدد فقراتها (41) فقرة.

ثبات الأداة:

للتحقق من ثبات أداة القياس تم فحص الاتساق الداخلي والثبات لفقرات الاستبانة بحساب معامل كرونباخ ألفا

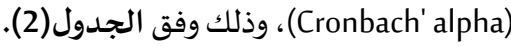
جدول (2): مصفوفة معاملات الثبات لأبعاد مجالات الدراسة والدرجة الكلية حسب معاملات الثبات كرونباخ ألفا.

\begin{tabular}{|c|c|c|}
\hline قيمة ألفا & عدد الفقرات & مجالات الدراسة \\
\hline 0.911 & 5 & تنمية روح العمل الجماعي \\
\hline 0.789 & 4 & التوعية الوطنية \\
\hline 0.655 & 5 & التوعية السياسية \\
\hline 0.884 & 5 & التوعية الاجتماعية \\
\hline 0.899 & 5 & التوعية الاقتصادية \\
\hline 0.821 & 6 & تعديل الاتجاهات لدى المواطنين \\
\hline 0.666 & 5 & خلق الشخصية الإيجابية \\
\hline 0.939 & 6 & خلق الثقة لدى المواطنين \\
\hline 0.963 & 41 & الدرجة الكلية \\
\hline
\end{tabular}


من خلال النظر إلى جدول(2) يتبين أن معاملات ثبات أداة الدراسـة في كل مجالات الدراسـة تراوحت بين (0.666) و(0.939)، وقد حصل مجال خلق الثقة لدى المواطنين على أعلى معامل ثبات في حين حصل مجال خلق الشخصية الإيجابية على أدنى معامل ثبات، وأخيراً بلغت قيمة ألفا على الدرجة الكلية (0.963)، مما يشير إلى دقة أداد أداة القياس.

\section{المعالجة الإحصائية:}

بعد جمع بيانات الدراسـة قام الباحثان بمراجعتها وذلك تمهيدا لإدخالها للحاسب وقد تم إدخالها للحاسب وذلك

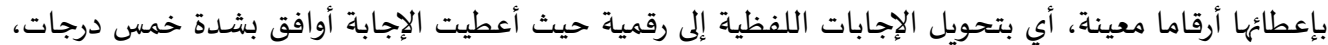

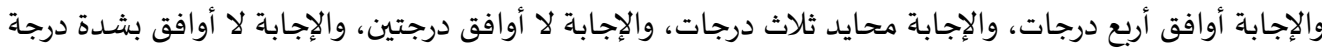

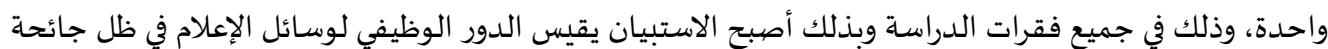
كورونا بالاتجاه الموجب. وتمت المعالجة الإحصائية للبيانات باستخراج الأعداد، المتوسطات الحسابية والانحرافات

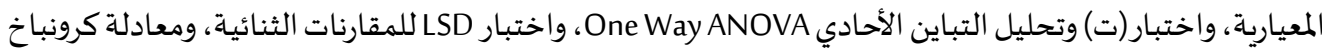

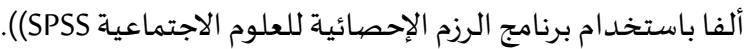

\section{نتائج الدراسة ومناقشتها وتفسيرها والتوصيات:}

يتناول هذا المبحث عرضاً للنتائج التي توصل إليها الباحثين من خلال استجابة أفراد عينة الدراسة حول الدور الوظيفي

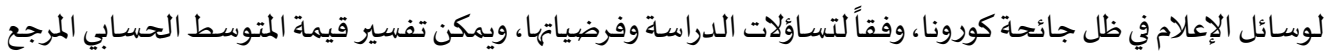
للعبارات في أداة الدراسة كما يلي: لوساتي

جدول (3): دلالة المتوسط الحسابي.

\begin{tabular}{|c|c|c|}
\hline الدلالة حسب الاستبانة & الدلالة & المتوسط الحسابي \\
\hline لا أوافق بشدة & منخفض جداً & $1.79-1$ \\
\hline لا لا أوافق & منخفض & $2.59-1.80$ \\
\hline 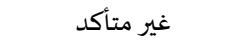 & متوسط & $3.39-2.60$ \\
\hline أوافق & مرتفع & $4.19-3.40$ \\
\hline أوافق بشدة & مرتفع جداً & $5.00-4.20$ \\
\hline
\end{tabular}

وفي ضهوء معالجة بيانات الدراسة إحصائيا توصل الباحثان للنتائج الآتية:

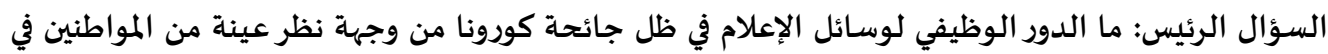
محافظة الخليل؟، ولإجابة عن هذا السؤال فقد تم استخراج المتوسطات الحسابية والانحرافات المعيارية والدرجة

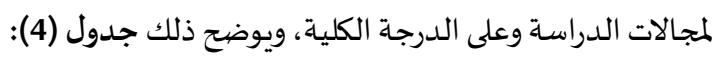

\begin{tabular}{|c|c|c|c|}
\hline 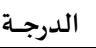 & الانحراف المعياري & المتوسط الحسـابي & مجالات الدراسة \\
\hline 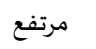 & 0.849 & 3.73 & التوعية الاجتماعية \\
\hline 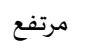 & 0.914 & 3.45 & التوعية الوطنية \\
\hline 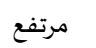 & 0.953 & 3.43 & تنمية روح العمل الجماعي \\
\hline متوسط & 1.16 & 3.13 & خلق الثقة لدى المواطنين \\
\hline متوسط & 0.774 & 3.12 & خلق الشخصية الإيجابية \\
\hline متوسط & 0.904 & 3.09 & التوعية السياسية \\
\hline متوسط & 0.803 & 3.06 & تعديل الاتجاهات لدى المواطنين \\
\hline متوسط & 1.02 & 3.02 & التوعية الاقتصادية \\
\hline متوسط & 0.748 & 3.21 & الدرجة للدور الوظيفي لوسائل الإعلام \\
\hline
\end{tabular}


بالنظر إلى جدول (4) يتضح وجود دور وظيفي متوسط لوسائل الإعلام في ظل جائحة كورونا بمتوسط حسابي (3.21) وانحراف معياري (0.748). وجاءت أعلى مجالات الدور الوظيفي مجال التوعية الاجتماعية بمتوسط حسابي (3.73)

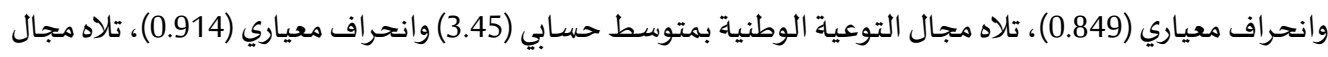

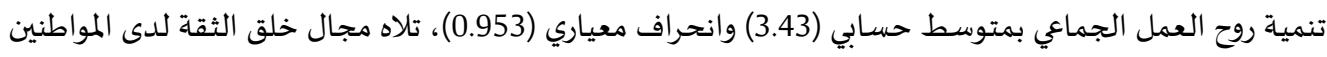

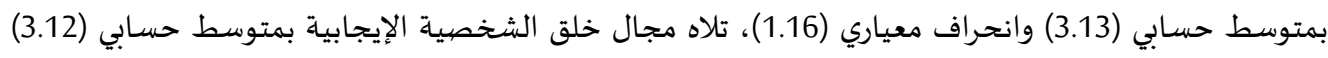
وانحراف معياري (0.774)، تلاه مجال التوعية السياسية بمتوسط حسابي (3.09) وانحراف معياري (0.904)، تلاه مجال تعديل الاتجاهات لدى المواطنين بمتوسط حسابي (3.06) وانحراف معياري (0.803)، وأخيراً مجال التحال التوعية

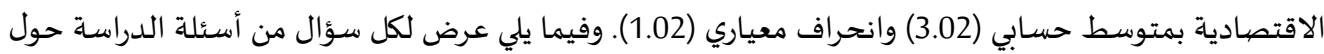
الدور الوظيفي لوسائل الإعلام:

س1) ما دوروسائل الإعلام في تنمية روح العمل الجماعي لدى المواطنين في محافظة الخليل؟ جدول (5): المتوسطات الحسابية والانحر افات المعيارية حول دوروسائل الإعلام في تنمية روح العمل

\begin{tabular}{|c|c|c|c|}
\hline \multicolumn{4}{|c|}{ الجماعي حسب الأهمية. } \\
\hline 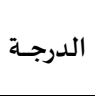 & المعياري & المستوسط & 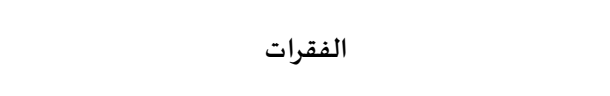 \\
\hline 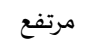 & 1.10 & 3.50 & إنشاء مبادرات مجتمعية ميدانية تحفّز العمل الجماعي \\
\hline 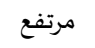 & 1.19 & 3.49 & عرض تجارب ناجحة لأفراد ساهموا في إنجازات جماعية \\
\hline 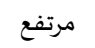 & 1.10 & 3.45 & البرامج التي تحفز على العمل الجماعي \\
\hline متوسط & 1.09 & 3.38 & الندوات واللقاءات التي تحث على العمل ضمن الفريق \\
\hline متوسط & 1.05 & 3.31 & التعاون بين الوسائل الإعلامية كمثال للحث على العمل الجماعي \\
\hline
\end{tabular}

بالنظر إلى الجدول(5) يتبين أن أعلى فقرات تنمية روح العمل الجماعي كانت الفقرة التي تنص على (إنشاء مبادرات مجتمعية ميدانية تحفّز العمل الجماعي) بمتوسط حسابي (3.50) وانحراف معياري (1.10)، تلاه الفقرة التي تنص على النى (عرض تجارب ناجحة لأفراد ساهموا في إنجازات جماعية) بمتوسط حسابي (3.49) وانحراف معياري (1.19)، وأخيراً

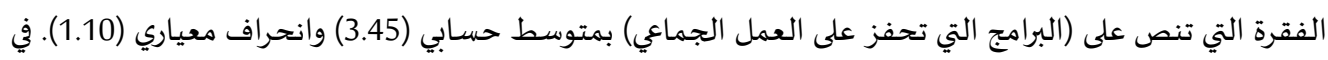

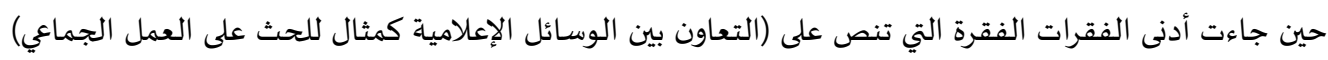

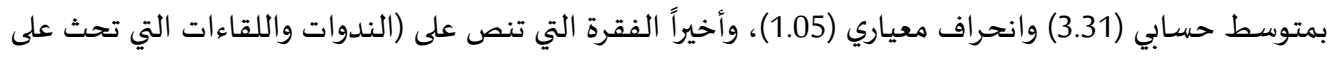
العمل ضمن الفريق) بمتوسط حسابي (3.38) وانحراف معياري (1.09).

س2) ما دوروسائل الإعلام في التوعية الوطنية لدى المواطنين في محافظة الخليل؟ جدول (6): المتوسطات الحسابية والانحر افات المعيارية حول دوروسائل الإعلام في التوعية الوطنية حسب الأهمية.

\begin{tabular}{|c|c|c|c|}
\hline 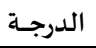 & الانحراف المعياري & المتوسط الحسـابي & 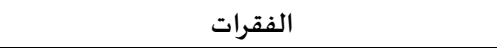 \\
\hline 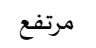 & 1.07 & 3.72 & تكرار الدعايات الخاصة بالتوعية الوطنية \\
\hline 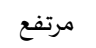 & 1.18 & 3.54 & إبراز دور الدولة في التعامل مع الجائحة \\
\hline متوسط & 1.17 & 3.36 & دعم نشطاء يدعمون ويؤكدون على التوعية الوطنية \\
\hline متوسط & 1.23 & 3.32 & التعاون المشترك بين وسائل الإعلام المختلفة \\
\hline
\end{tabular}

بالنظر إلى الجدول(6) يتبين أن أعلى فقرات التوعية الوطنية كان الفقرة التي تنص على (تكرار الدعايات الخاصة بالتوعية الوطنية) بمتوسط حسابي (3.72) وانحراف معياري (1.07)، وأخيراً الفقرة التي تنص على (إبراز دور الدولة في

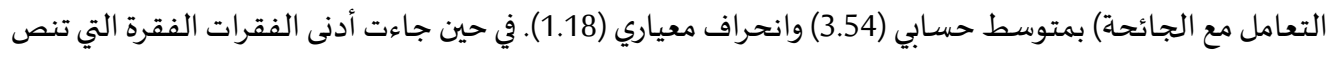
على (التعاون المشترك بين وسائل الإعلام المختلفة) بمتوسط حسابي (3.32) وانحراف معياري (1.23)، وأخيراً الفقرة التي تنص على (دعم نشطاء يدعمون ويؤكدون على التوعية الوطنية) بمتوسط حسابي (3.36) وانحراف معياري 
س3) ما دوروسائل الإعلام في التوعية السياسية لدى المواطنين في محافظة الخليل؟ جدول (7): المتوسطات الحسابية والانحر افات المعيارية حول دوروسائل الإعلام في التوعية السياسية حسب الأهمية.

\begin{tabular}{|c|c|c|c|}
\hline 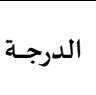 & الانحراف المعياري & المتوسط الحسبي & 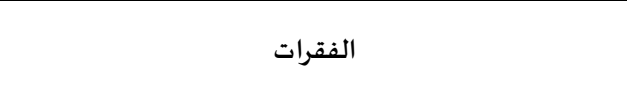 \\
\hline متوسط & 1.31 & 3.09 & إبراز عمل حزب مقابل الآخر في التعامل مع الجائحة \\
\hline متوسط & 1.24 & 2.99 & اتحاد الوسائل الإعلامية للتعامل مع الجائحة \\
\hline متوسط & 1.28 & 2.80 & توحيد الرواية السياسية بين الوسائل الإعلامية \\
\hline 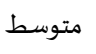 & 1.32 & 2.77 & الالتزام بالحيادية والنزاهة في العمل الإعلامي أثناء الأزمة \\
\hline متوسط & 1.11 & 2.68 & التركيز على القضايا السياسية الداخلية دون التركيز على الجائحة \\
\hline
\end{tabular}

بالنظر إلى الجدول(7) يتبين أن أعلى فقرات التوعية السياسية كانت الفقرة التي تنص على (إبراز عمل حزب مقابل

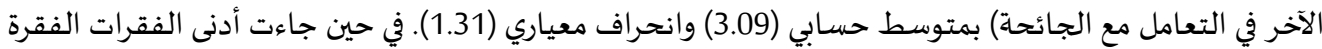
التي تنص على (التركيز على القضايا السياسية الداخلية دون التركيز على الجائحة) بمتوسط حسابي (2.68) وانحراف معياري (1.11).

س4) ما دوروسائل الإعلام في التوعية الاجتماعية لدى المواطنين في محافظة الخليل؟ جدول (8): المتوسطات الحسابية والانحر افات المعيارية حول دوروسائل الإعلام في التوعية الاجتماعية حسب الأهمية.

\begin{tabular}{|c|c|c|c|}
\hline 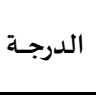 & الانحراف & المستوسطي & 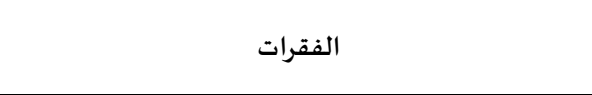 \\
\hline 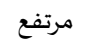 & 0.796 & 4.11 & ت تعزيز مفاهيم الوقاية من الفيروس \\
\hline 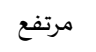 & 1.05 & 3.89 & توضيح المفاهيم الخاصة بجائحة كورونا للمجتمع \\
\hline 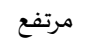 & 0.993 & 3.81 & الاستمرار في التوعية الاجتماعية منذ بداية الجائحة \\
\hline مرتفع & 1.05 & 3.43 & تسليط الضوء على نماذج مجتمعية نجحت في تجاوز الجائحة \\
\hline مرتفع & 1.19 & 3.40 & المساعدة على تلاحم المجتمع وتكاتفه في التعامل مع الجائحة \\
\hline
\end{tabular}

بالنظر إلى الجدول(8) يتبين أن أعلى فقرات التوعية الاجتماعية كانت الفقرة التي تنص على (تعزيز مفاهيم الوقاية من الفيروس ) بمتوسط حسابي (4.11) وانحراف معياري (0.796)، تلتها الفقرة التي تنص على (توضيح المفاهيم

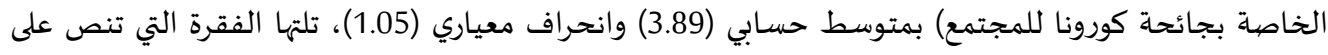

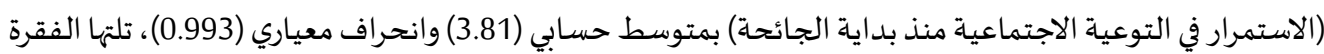
التي تنص على (تسليط الضوء على نماذج مجتمعية نجحت في تجاوز الجائحة كهدف للتوعية الاجتماعية) بمتوسط حسابي (3.43) وانحراف معياري (1.05)، وأخيراً الفقرة التي تنص على (المساعدة على تلاحم المجتمع وتكاتفاه في التعامل مع الجائحة) بمتوسط حسابي (3.40) وانحراف معياري (1.19).

س5) ما دوروسائل الإعلام في التوعية الاقتصادية لدى المواطنين في محافظة الخليل؟ جدول (9): المتوسطات الحسابية والانحر افات المعيارية حول دوروسـائل الإعلام في التوعية الاقتصهادية حسب الأهمية.

\begin{tabular}{|c|c|c|c|}
\hline الدرجــة & الانحراف & المتوسط الحسـابي & 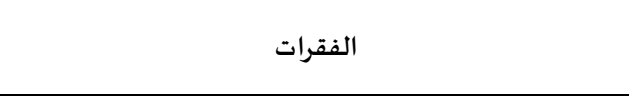 \\
\hline متوسط & 1.25 & 3.10 & نشر تحديث للحالة الاقتصادية المحلية بشكل مستمر \\
\hline متوسط & 1.22 & 3.05 & التحكم بالمحتوى الإعلامي ليتناسب مع الوضع الاقتصـادي المحلي \\
\hline متوسط & 1.24 & 3.04 & استخدام الدعاية الإعلامية في توعية المجتمع اقتصاديا \\
\hline متوسط & 1.15 & 3.01 & ترشيد الاستهلاك من خلال وسـائل التواصل الاجتماعي \\
\hline
\end{tabular}




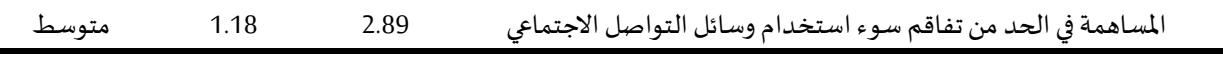

بالنظر إلى الجدول(9) يتبين أن أعلى فقرات التوعية الاقتصادية كانت الفقرة التي تنص على (نشر تحديث للحالة

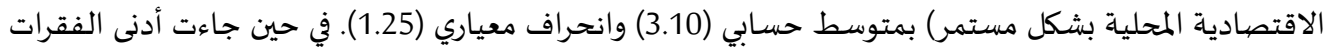
الفقرة التي تنص على (المساهمة في الحد من تفاقم سوء استخدام وسائل التواصل الاجتماعي) بمتوسط حسابي (2.89) وانحراف معياري (1.18).

س6) ما دوروسائل الإعلام في تعديل الاتجاهات لدى المواطنين في محافظة الخليل؟ جدول (10): المتوسطات الحسابية والانحر افات المعيارية حول دوروسائل الإعلام في تعديل الاتجاهات حسب الأهمية.

\begin{tabular}{|c|c|c|c|}
\hline الدرجـة & الانحراف & المتوسط الحسبي & 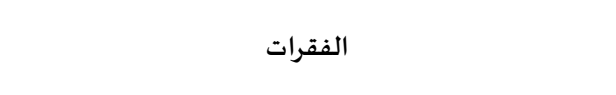 \\
\hline متوسط & 1.11 & 3.24 & بث برامج تعزز السلوك الإيجابي لدى الفرد. \\
\hline متوسط & 1.11 & 3.18 & بث برامج تساهم في إحداث التغيير في المجتمع \\
\hline 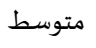 & 1.10 & 3.05 & بث برامج تؤثر في تعديل الاتجاهات والمواقف. \\
\hline متوسط & 1.11 & 3.04 & بث برامج تؤثر على مواقف الجماهير وحكمههم على الأشياء \\
\hline متوسط & 1.04 & 2.95 & بث برامج تؤثر سلبا على تشخيص الأحداث والمتغيرات الأساسية. \\
\hline متوسط & 1.14 & 2.90 & بث برامج تؤثر على المعتقدات والقيم. \\
\hline
\end{tabular}

بالنظر إلى الجدول(10) يتبين أن أعلى فقرات تعديل الاتجاهات كانت الفقرة التي تنص على (بث برامج تعزز السلوك الإيجابي لدى الفرد) بمتوسط حسابي (3.24) وانحراف معياري (1.11). في حين جاءت أدنى الفقرات الفقرة التي تنص على (بث برامج تؤثر على المعتقدات والقيم) بمتوسط حسابي (2.90) وانحراف معياري (1.14).

س7) ما دوروسائل الإعلام في خلق الشخصية الإيجابية لدى المواطنين في محافظة الخليل؟ جدول (11): المتوسطات الحسابية والانحر افات المعيارية حول دوروسائل الإعلام في خلق الشخصية الإيجابية حسب الأهمية.

\begin{tabular}{|c|c|c|c|}
\hline الدرجـة & الانحراف المعياري & المتوسط الحسابي & 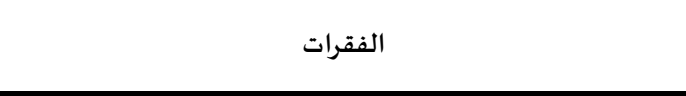 \\
\hline متوسط & 1.12 & 3.37 & المسساهمة في إبراز شخصيات مجتمعية على الساحة الإعلامية \\
\hline متوسط & 1.29 & 3.27 & تمجيد شخصيية دون الأخرى بسبب الانتماء السياسي للوسيلة الإعلامية \\
\hline متوسط & 1.19 & 3.13 & خلق شخصية مرنة ونشطة تتقبل النقد بسهولة \\
\hline متوسط & 1.12 & 3.10 & تجاوز السياسة الإعلامية للوصول إلى مصداقية في النشر \\
\hline متوسط & 1.17 & 2.75 & نقد الشخصيات الإعلامية بمهنية \\
\hline
\end{tabular}

بالنظر إلى الجدول(11) يتبين أن أعلى فقرات تعديل الاتجاهات لدى المواطنين كانت الفقرة التي تنص على (المساهمة

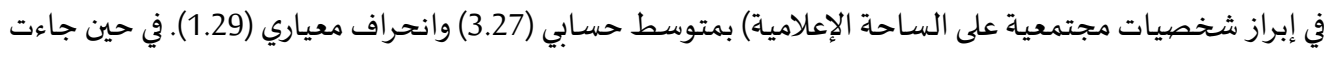
أدنى الفقرات الفقرة التي تنص على (نقد الشخصيات الإعلامية بمهنية) بمتوسط حسابي (2.75) وانحراف معياري

س8) ما دوروسائل الإعلام في خلق الثقة لدى المواطنين في محافظة الخليل؟ جدول (12): المتوسطات الحسابية والانحر افات المعيارية حول دوروسائل الإعلام في خلق الثقة حسب الأهمية.

\begin{tabular}{|c|c|c|c|}
\hline 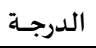 & الانحراف المعياري المياف & المتوسط الحسابي & 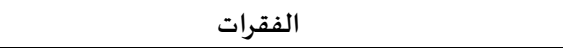 \\
\hline متوسط & 1.34 & 3.27 & المصداقية في نشر الأخبار المتعلقة بجائحة كورونا \\
\hline متوسط & 1.27 & 3.22 & التعامل مع المصابين بالفيروس بمهنية أثناء الطرح الإعلامي \\
\hline
\end{tabular}




\begin{tabular}{|c|c|c|c|}
\hline متوسط & 1.30 & 3.18 & الابتعاد عن "التلاسن" الإعلامي بين الوسائل الإعلامية \\
\hline \multirow[t]{2}{*}{ متوسط } & 1.33 & 3.15 & تنشئة الأفراد من خلال غرس عادات صالحـة تؤدي إلى مشاركة \\
\hline & & & 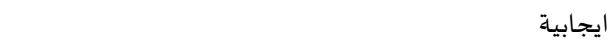 \\
\hline متوسط & 1.37 & 3.02 & المسـاهمة في تعزيز الثقة للشخص المناسب في المكان المناسب \\
\hline متوسط & 1.36 & 2.97 & خلق وسائل اتصال مباشرة ما بين المواطن وأصحاب القرار \\
\hline
\end{tabular}

بالنظر إلى الجدول(12) يتبين أن أعلى فقرات خلق الثقة لدى المواطنين كانت الفقرة التي تنص على (المصديداقية في نشر

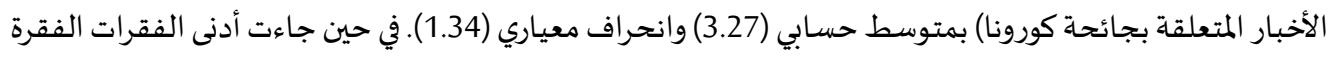

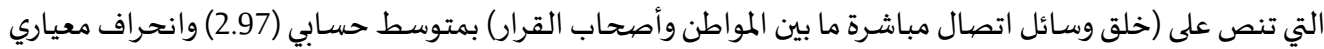

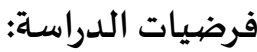

لا توجد فروق ذات دلالة إحصائية عند مستوى الدلالة ( 1 ( $)$ في الدور الوظيفي لوسائل الإعلام وفق متغيرات:

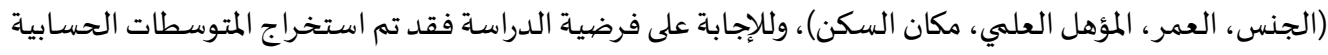

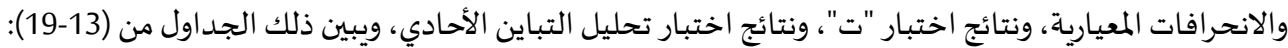

حسب متغير الجنس:

جدول (13): نتائج اختبار"ت" للفروق في الدور الوظيفي لوسائل الإعلام تبعاً لمتغير الجنس.

\begin{tabular}{|c|c|c|c|c|c|c|}
\hline الإحصائية الدلالة & قيمة ت & الحربة & الانحراف المعياري & المتوسط الحسابي & العدد & الجنس \\
\hline \multirow{2}{*}{0.078} & \multirow{2}{*}{$1.774-$} & 88 & 0.747 & 3.13 & 89 & ذ كر \\
\hline & & 50 & 0.734 & 3.36 & 51 & أنثى \\
\hline
\end{tabular}

بالنظر إلى جدول (13) يتضح أن نتائج الدراسة أظهرت عدم وجود فروق ذات دلالة إحصائية عند مستوى الدلالة

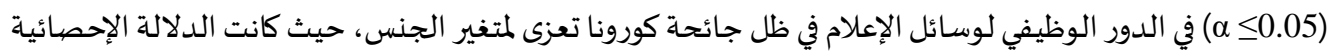

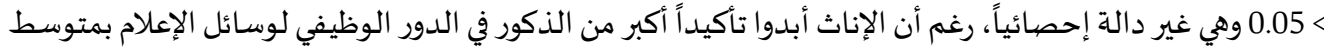

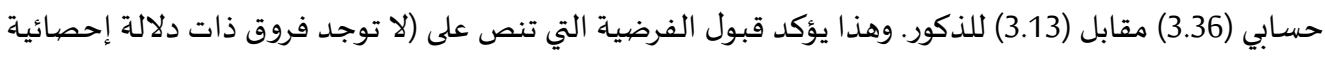
عند مستوى الدلالة ( 0.05 (3 ) في الدور الوظيفي لوسائل الإعلام وفق متغير الجنس).

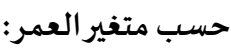
جدول(14): نتائج اختبار تحليل التباين الأحادي للفروق في الدور الوظيفي لوسائل الإعلام في ظل جائحة كورونا تبعا لمتغير: العمر.

\begin{tabular}{|c|c|c|c|c|c|c|c|c|c|}
\hline 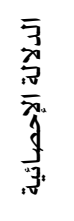 & 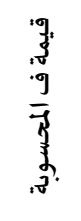 & $\frac{3}{3}$ & $\begin{array}{l}\hat{5} \\
\overline{3} \\
\overline{3} \\
3\end{array}$ & $\begin{array}{c}\frac{3}{3} \\
\frac{3}{3} \\
\frac{3}{3} \\
\frac{3}{3}\end{array}$ & $\begin{array}{l}\frac{g}{3} \\
\frac{5}{3} \\
\frac{3}{3}\end{array}$ & المعياري & الحسابي & العدد & العمر \\
\hline & & 2.352 & 4 & 9.407 & $\frac{3}{y}$ & 0.692 & 3.45 & 73 & أقل من 30 عاماً \\
\hline 0.002 & 4.634 & 0.508 & 135 & 68.517 & $\sqrt{3}$ & 0.513 & 2.93 & 21 & من 40-30عاماً \\
\hline
\end{tabular}




\begin{tabular}{|c|c|c|c|c|c|}
\hline & 0.624 & 3.09 & 15 & من 50-60عاماً \\
\hline & & 1.14 & 2.76 & 9 & فوق60 عاماً \\
\hline 139 & 77.926 & 0.748 & 3.21 & 140 & المجموع \\
\hline
\end{tabular}

بالنظر إلى جدول (14) يتضيح أن نتائج الدراسة أظهرت وجود فروق ذات دلالة إحصائية عند مستوى الدلالة (0.05 الدائل

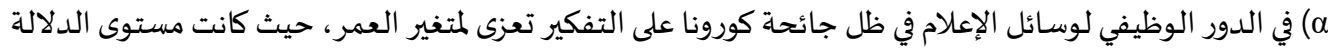

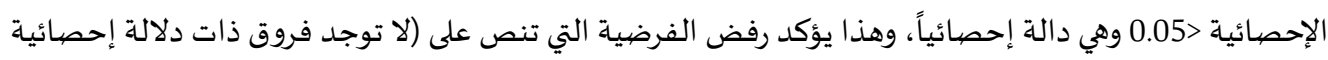

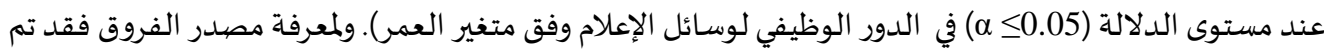

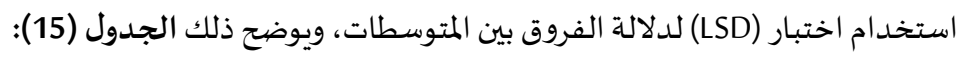
جدول(15):اختبار (LSD) لدلالة الفروق في الدور الوظيفي لوسائل الإعلام حسب العمر.

\begin{tabular}{|c|c|c|c|c|c|}
\hline فوق 60 عام & 60-51 عام & 50-41 عام & 40-30 عام & دون 30 عام & العمر \\
\hline \multirow[t]{5}{*}{$*_{0.69461}$} & & $*_{0}^{*} .49840$ & $*_{0} 0.52033$ & & دون 30 عام \\
\hline & & & & $-* 0.52033$ & 40-30 عام \\
\hline & & & & $-* 0.49840$ & 50-41 عام \\
\hline & & & & & 60-51 عام \\
\hline & & & & $-* 0.69461$ & فوق 60 عام \\
\hline
\end{tabular}

يتضح من الجدول(15) أن الفروق كانت ما بين المواطنين الذين أعمارهم (دون 30 عام) والذين كانت أعمارهم (30-

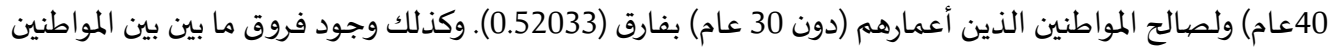

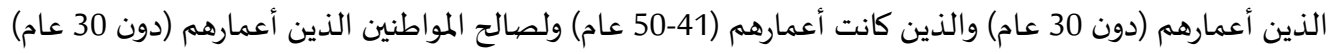

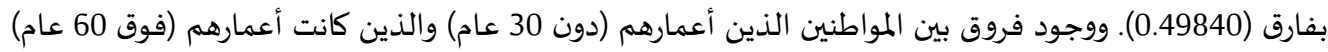

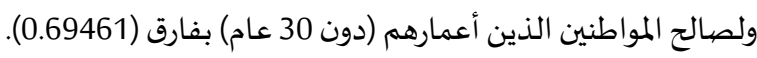

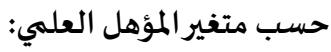

جدول(16): نتائج اختبار تحليل التباين الأحادي للفروق في الدور الوظيفي لوسائل الإعلام في ظل جائحة كورونا تبعا لمتغير: المؤهل العلمي.

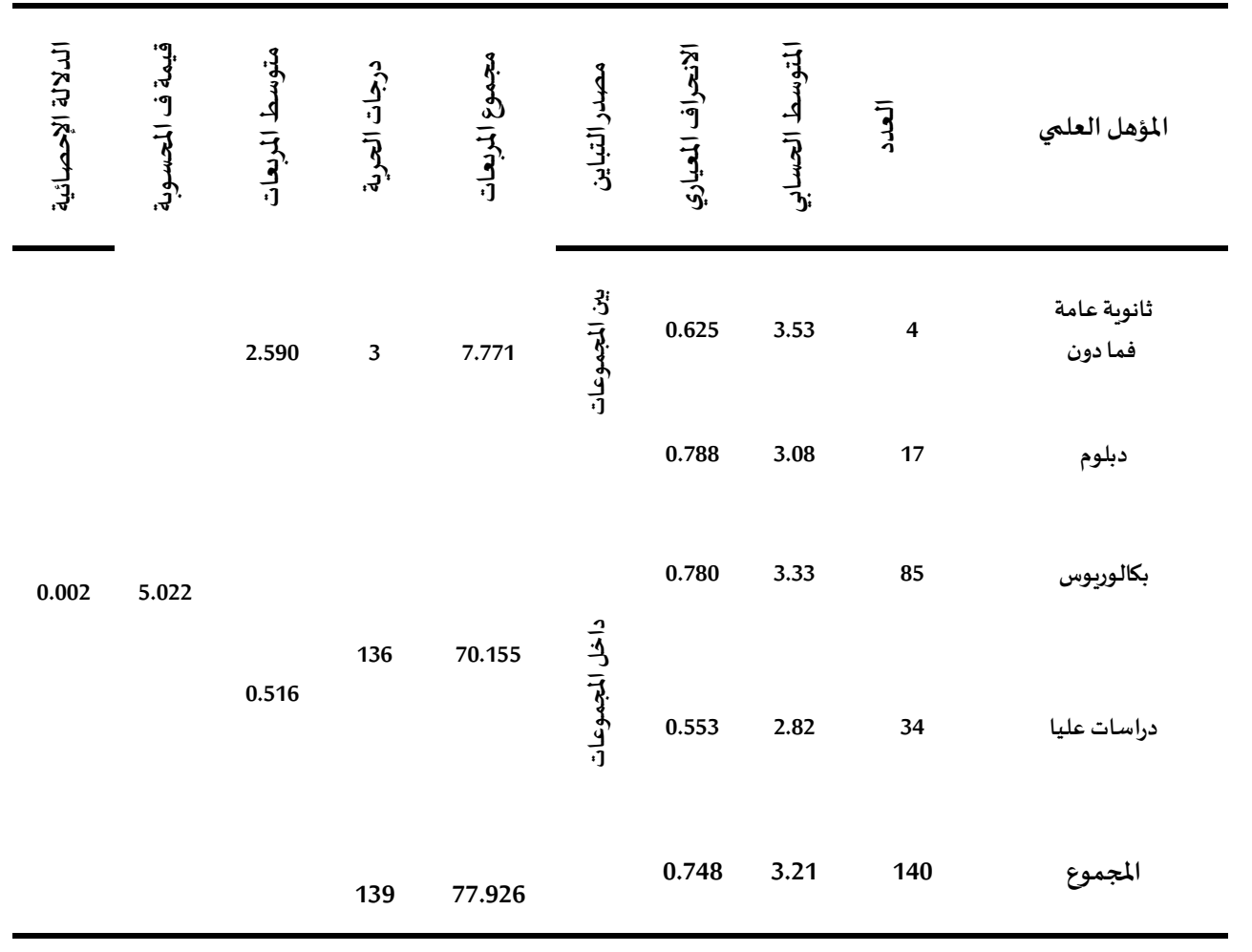

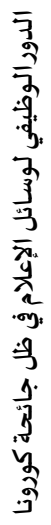


بالنظر إلى جدول (16) يتضح أن نتائج الدراسة أظهرت وجود فروق ذات دلالة إحصائية عند مستوى الدلالة ( 0.05

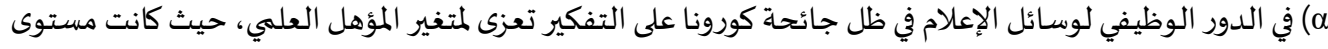

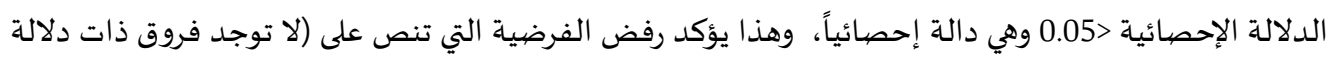

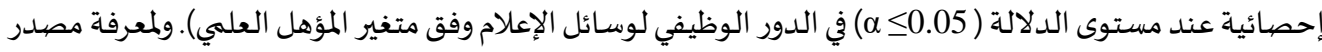

الفروق فقد تم استخدام اختبار (LSD) لدلالة الفروق بين المتوسطات، ويوضح ذلك الجدول (17):

\begin{tabular}{|c|c|c|c|c|}
\hline دراسـات عليا & بكالوريوس & دبلوم & ثانوية فأقل & المؤهل العلهي \\
\hline \multirow[t]{2}{*}{$*_{0}^{*} 0.70189$} & & & & ثانوية فأقل \\
\hline & & & & دبلوم \\
\hline \multirow[t]{2}{*}{$*_{0} 0.50447$} & & & & بكالوريوس \\
\hline & $-* 0.50447$ & & $-{ }^{*} 0.70189$ & دراسات عليا \\
\hline
\end{tabular}

يتضح من الجدول(17) أن الفروق كانت ما بين المواطنين الذين مؤهلهم العلمي ثانوية عامة فما دون، وما بين من

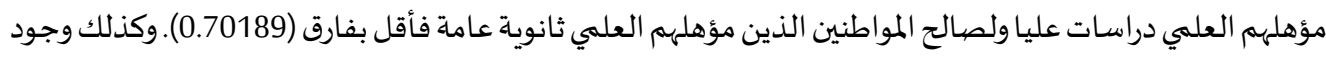
فروق ما بين بين المواطنين الذين مؤهلهم العلهي بكالوريوس والذين مؤهلهم العلمي دراسات عليا ولصالح المواطنين الذين مؤهلهم العلمي بكالوريوس بفارق (0.50447).

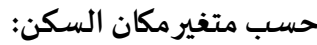

جدول(18): نتائج اختبار تحليل التباين الأحادي للفروق في الدور الوظيفي لوسائل الإعلام في ظل جائحة كورونا تبعا لمتغير: مكان السكن. المبن.

\begin{tabular}{|c|c|c|c|c|c|c|c|c|c|}
\hline 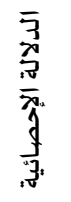 & 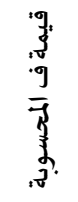 & $\frac{3}{3}$ & $\frac{3}{3}$ & $\frac{3}{3}$ & $\frac{\mathfrak{g}}{3}$ & $\begin{array}{l}\overline{7} \\
\frac{3}{9} \\
\overline{9} \\
\overline{3} \\
\overline{3} \\
\bar{y}\end{array}$ & $\begin{array}{l}\overline{3} \\
\frac{3}{3} \\
\frac{3}{3} \\
3 \\
3\end{array}$ & $\overline{3}$ & $\begin{array}{l}\frac{8}{6} \\
\overline{3} \\
\overline{3} \\
.3\end{array}$ \\
\hline \multirow{3}{*}{0.015} & \multirow{3}{*}{4.335} & 2.319 & 2 & 4.638 & 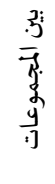 & 0.747 & 3.13 & 86 & "3. \\
\hline & & \multirow[t]{2}{*}{0.535} & 137 & 73.288 & \multirow{2}{*}{$\begin{array}{l}\frac{3}{3} \\
\overline{3} \\
\overline{3} \\
\frac{3}{3} \\
\frac{9}{3}\end{array}$} & 0.614 & 3.63 & 22 & 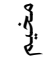 \\
\hline & & & 139 & 77.926 & & & & & 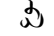 \\
\hline
\end{tabular}

بالنظر إلى جدول (18) يتضح أن نتائج الدراسة أظهرت وجود فروق ذات دلالة إحصائية عند مستوى الدلالة (0.05

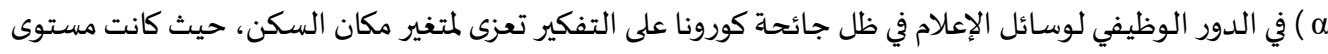

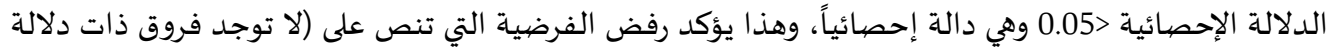

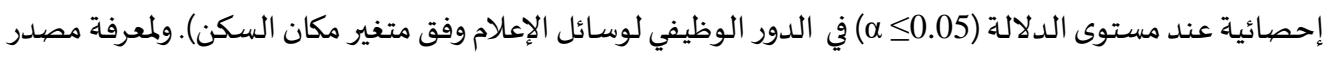

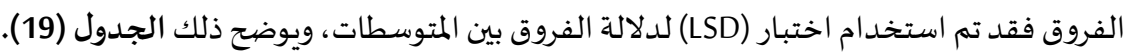




\begin{tabular}{|c|c|c|c|}
\hline مخيم & قرية & مدينة & مكان السكن \\
\hline$-* 0.50280$ & & & مدينة \\
\hline \multirow[t]{2}{*}{$-* 0.49236$} & & & قرية \\
\hline & ${ }^{*} 0.49236$ & $* 0.50280$ & مخيم \\
\hline
\end{tabular}

يتضح من الجدول(19) أن الفروق كانت ما بين المواطنين الذين يسكنون في المخيم والذين يسكنون في المدينة ولصالح

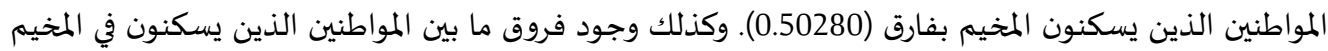

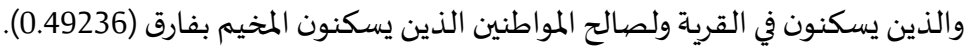

مناقشة نتائج والتوصيات:

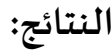

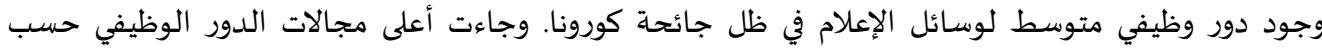

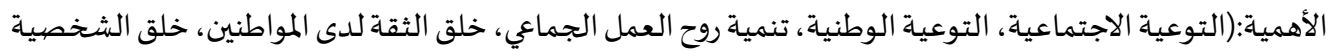

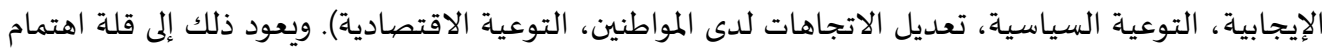

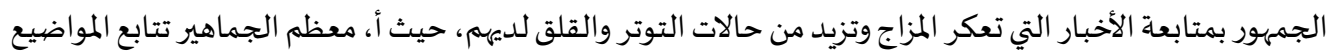

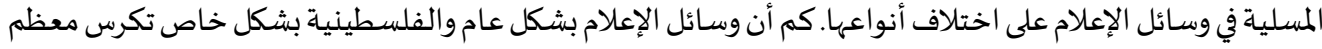

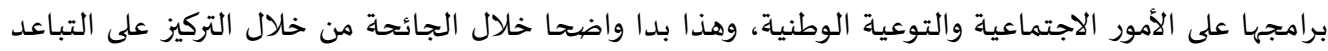

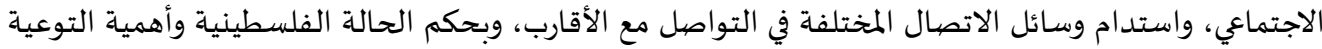
الوطنية في ظل وجود الاحتلال، فإن أغلب البرامج تكون موجهة نحو ذلك التان.

يوجد لوسائل الإعلام دور مرتفع في إنشاء مبادرات مجتمعية ميدانية تحفّز العمل الجماعي، وفي عرض تجارب ناجحة إنجا

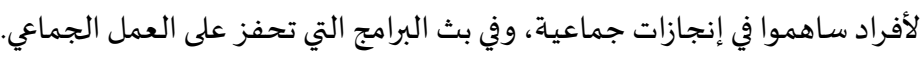

تعمل وسائل الإعلام على تكرار الدعايات الخاصة بالتوعية الوطنية في مختلف الوسائل الإعلامية، وكذلك إبراز دور الدولة في التعامل مع الجائحة، وبث البرامج التي تحفز العمل الجماعي.

تعمل وسائل الإعلام على تعزيز مفاهيم الوقاية من الفيروس، وكذلك توضيح المفاهيم الخاصة بجائحة كورونا للمجتمع، كما تحافظ على الاستمرار في التوعية الاجتماعية منذ بداية الجائحة. تسلط الضوء على نماذج مجتمعية نجحت في تجاوز الجائحة كهدف للتوعية الاجتماعية، وتساعد على تلاحم المجتمع وتكاتفاه في التعامل مع الجائحة.

أظهرت النتائج عدموجود فروق ذات دلالة إحصائية عند مستوى الدلالة (0.05 ه ) في الدور الوظيفي لوسائل الإعلام

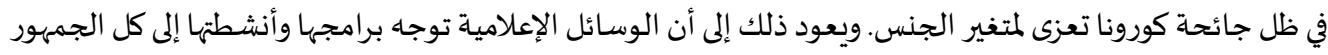
بغض النظر عن جنسه ذكراً كان أم أنثى.

وأظهرت النتائج وجود فروق ذات دلالة إحصائية عند مستوى الدلالة (0.05 م ) في الدور الوظيفي لوسائل الإعلام

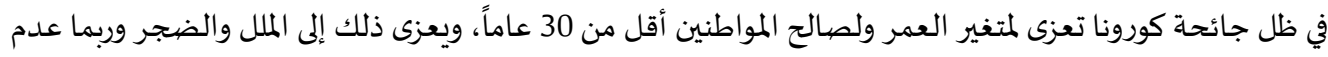

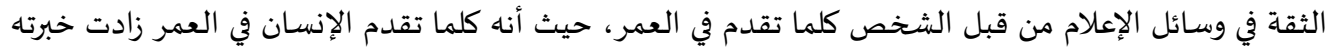

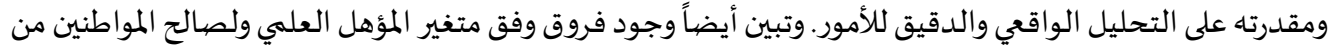

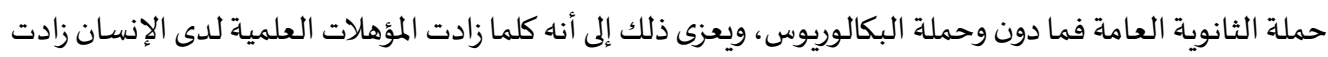


خبرته ومقدرته على التحليل الواقعي والدقيق للأمور. وأخيراً تبين وجود فروق وفق متغير السكن ولصالح المواطنين

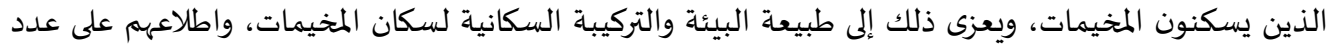

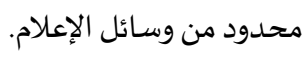

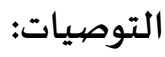

$$
\begin{aligned}
& \text { في ضيوء نتائج الدراسة وأهدافها يوصي الباحثان بما يلي: } \\
& \text { زيادة التعاون بين الوسائل الإعلامية كمثال للحث على العئل العمل الجماعي. } \\
& \text { • عقد المزيد من الندوات واللقاءات التي تحث على العمل ضمن الفريق. } \\
& \text { تعزيز التعاون المشترك بين وسائل الإعلام المختلفة للخروج ببرنامج موحد للتوعية الوطنية. } \\
& \text { دعم النشطاء الذين يدعمون ويؤكدون على التوعية الوطنية. } \\
& \text { المساواة في إبراز عمل الأحزاب السياسية في التعامل مع الجائحة. } \\
& \text { موازاة التركيز على القضايا السياسية الداخلية وجائحة كورونا. } \\
& \text { نشر تحديث للحالة الاقتصادية المحلية بشكل مستمر. } \\
& \text { المساهمة في الحد من تفاقم سوء استخدام وسائل التواصل الاجتماعي للحديث عن التراجع الاقتصادي. } \\
& \text { بث برامج تؤثر تعزز السلوك الإيجابي لدى الفرد، وتؤثر على المعتقدات والقيم. } \\
& \text { زيادة المساهمة في إبراز شخصيات مجتمعية على الساحة الإعلامية. } \\
& \text { ضرورة نقد الشخصيات الإعلامية بمهنية والابتعاد عن التحيز. }
\end{aligned}
$$

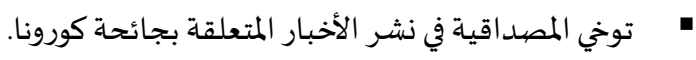

$$
\begin{aligned}
& \text { خلق وسائل اتصال مباشرة ما بين المواطن وأصحاب القرار. }
\end{aligned}
$$




\section{قائمة المصادرو المراجع}

\section{أولا: المراجع العربية}

$$
\text { بدوي، أحمد زكي (1994). معجم مصطلحات الإعلام(ط2). بيروت: دار الكتاب اللبناني. }
$$

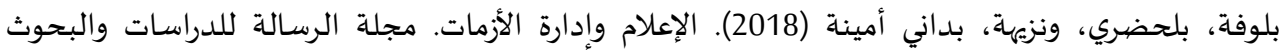

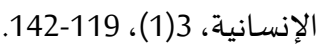

بلونيس، شيماء (2015). دور وسائل الإعلام والاتصالات الجديدة في التغيير السياسي (رسالة ماجستير غير منشورة)، كلية الحقوق والعلوم السياسية، جامعة أم البواقي، الجزائر.

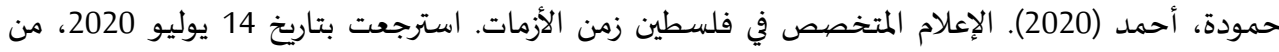
https://nn.ps/news/Artical/2020/04/18/302250/.

الحيارى، إيمان (2016). تعريف الإعلام. استرجعت بتاريخ 10 يوليو 2020، من https://mawdoo3.com.

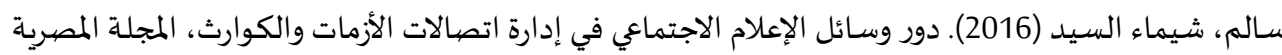

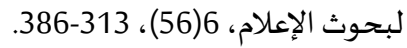

شبكة النبأ المعلوماتية (2020). الدور الوظيفي للإعلام في معالجة الأزمات والكوارث. استرجعت بتاريخ 29 مارس https://annabaa.org/arabic/studies/22681. 2020 من من من

الشمري، محمد (2018). تأثير الإعلام الجديد على الأمن الأسري، المجلة الإلكترونية الشـاملة متعددة التخصصيات،

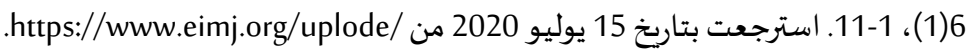
صادق، محمد عادل (2007). الصحافة وإدارة الأزمات، مدخل نظري تطبيقي(ط1). القاهرة: دار الفجر للنشر والتوزبع.

عايد، كمال (2017). تكنولوجيا الإعلام والاتصال وتأثيراتها على قيم المجتمع الجزائري-الشباب الجامعي لتلمسان أنموذجاً (أطروحة دكتوراه غير منشورة)، جامعة أبي بكر بلقايد، تلمسان، الجنانيان الجزائر.

عشماوي، محمد عبد الوهاب حسن (2008). دور الصحف في إدارة الأزمات/دراسة تطبيقية على جريمة الثأر. الإسكندرية: منشأة المعارف. مدمد عبد الوهاب.

محمود، يوسف (2003). تخطيط برامج الأزمات. مجلة الدراسات العليا بأكاديمية مبارك للأمن، 9(1)، 134-136. ميرزا، جاسم خليل (2006). الإعلام الأمني بين النظرية والتطبيق (ط1). القاهرة: مركز الترات الكتاب للنشر.

هانز، فيرز (1961). معجم اللغة العربية المعاصر. استرجعت بتاريخ 15 يوليو 2020 من من https://ontology.birzeit.edu/term/

الموسوعة الحرة (2020). جائحة فايروس كورونا. استرجعت بتاريخ 15 يوليو 2020 من https://ar.wikipedia.org/wiki/

\section{ثانيا: المراجع العربية المترجمة}

Ashmawi, M. (2008). The role of newspapers in crisis management-an applied study on the crime of revenge. Alexandria: Knowledge Facility.

Alhayari, I. (2016). Definition of media. Retrieved on July 10, 2020, from https://mawdoo3.com.

Al-Shommari, M. (2018). The Impact of New Media on Family Security, Comprehensive Multidisciplinary Online Journal, 6 (1), 1-11. Retrieved on July 15, 2020, from https://www.eimj.org/uplode/. 
Al Nab'a Informatics Network. (2020). Functional role of the media in dealing with crises and disasters. Retrieved on March 29, 2020, from https://annabaa.org/arabic/studies/22681.

Ayed, K. (2017). Information and communication technology and its effects on the values of the Algerian society - university youth of Tlemcen as a model (Unpublished doctoral thesis), Abi Baker Belkaid University, Tlemcen, Algeria.

Badawi, A. (1994). Glossary of Media Terminology (2ed). Beirut: Lebanese Book House.

Beloufa, B, \& Naziha, B. (2018). Media and Crisis Management. Al-Resalah Journal for Humanitarian Studies and Research, 3 (1), 119-142.

Blounis, Sh. (2015). The Role of New Media and Communication in Political Change (Unpublished Master Thesis), Faculty of Law and Political Science Oum Elbawaki University, Algeria.

Hammouda, A. (2020). Specialized media in Palestine in times of crises. Retrieved on July 14, 2020, from https://nn.ps/news/Artical/2020/04/18/302250/.

Mahmoud, Y. (2003). Crisis Program Planning. Postgraduate Journal of Mubarak Security Academy, $9(1), 134-136$

Mirza, J. (2006). Security media between theory and practice (1ed). Cairo: Book Center for Publishing. Salem, Sh. (2016). The Role of Social Media in Crisis and Disaster Communications Management, Egyptian Journal of Media Research, 6 (56), 313-386.

Hans Fairs (1961). A Dictionary of Contemporary Arabic Language. Retrieved on 15 July 2020 from https://ontology.birzeit.edu/term/

Free Encyclopedia (2020). Coronavirus pandemic. Retrieved on July 15, 2020, from https://ar.wikipedia.org/wiki/ 